\title{
A Longitudinal Analysis of Self-Perceived Social Communication Competence Profiles of Korean Multicultural Adolescents according to Regional Size, Cultural and Linguistic Background: Middle and High School Students
}

Eun Ju Lee

The Special Education Research Institute (SERI), Ewha Womans University, Seoul, Korea

Correspondence: Eun Ju Lee, PhD

The Special Education Research Institute (SERI), Ewha Womans University, 52 Ewhayeodae-gil, Seodaemun-gu, Seoul 03760, Korea

Tel: $+82-10-7335-1953$

Fax: +82-2-3277-2679

E-mail:imfedra@naver.com

Received: January 5, 2021

Revised: February 5, 2021

Accepted: February 17, 2021

This work was supported by the Ministry of Education of the Republic of Korea and the National Research Foundation of Korea (No. NRF2020S1A5B5A16082517)
Objectives: This study was analyzed using the data of 2013 Korean Educational Longitudinal Study (KELS), a Korean adolescents panel study, to examine the social communication competence (SCC) of Korean multicultural adolescents according to residential area, linguacultural background. Methods: Group differences for the SCC questionnaire assessment and scores were analyzed using MANOVAs with group (two levels: multicultural adolescents, monocultural adolescents) as a between factor (regional size, birth regions, language of use). Results: 1) Multicultural adolescents were significantly lower in the evaluation of 'easy and accurate speaking or giving examples in consideration of listeners' compared to monocultural adolescents $\left(F=5.23^{*}, p<.05 ; F=7.78^{* *}, p<.005\right)$. 2) As a result of analyzing the interaction of the SCC assessment according to the culture group and regional area, multicultural adolescents living in Seoul had higher SCC scores and questionnaires than monocultural adolescents, but multicultural adolescents living in metropolitan cities had a much lower overall SCC evaluation ( $\left.F=3.33^{*}, p=5.05\right)$. 3) The multicultural adolescents living in town and villages were significantly higher in terms of 'listening to friends' than those of other cultural and regional group $\left(F=2.96^{*}, p<.05\right)$. 4) The questionnaire of 'sympathy for thoughts and feelings of friends' was more likely to be evaluated by multicultural adolescents born in Korea than born in foreign countries $\left(F=2.76^{\dagger}, p=0.09\right)$. Conclusion: The SCC questionnaire assessment and scores were found to be influenced by residential area and linguacultural background factors. Therefore, clinicians should consider the SCC evaluation of multicultural adolescents and their interpretation of the evaluation results, as well as their residential and linguacultural background.

Keywords: Social communication competence, Multicultural Adolescents, 2013 KELS, Residential area, Linguaculture background
국내 다문화청소년은 다양한 집단적 특성을 지님에도 불구하고, 각 정부부처와 민간단체, 연구자 등 사회 전반에서 다문화가정 자 녀의 부족한 측면에 근거한 지원의 필요성을 강조한 결과, 국내 다 문화청소년들이 단일문화가정 출신의 청소년들에 비해 의사소통 발달적 측면에서 부족하고 결핍된 존재로 인식되는 사회적 현상을
초래하였다(National Youth Policy Institute, NYPI, 2020). 다문화 청소년의 의사소통 능력 발달 특성에 대한 보다 객관적이고 면밀한 분석 없이 이들에 대한 사회적 고정관념이 강화되는 현상이 지속 될 경우 한국사회의 사회적 통합에 저해요소로 작용될 가능성이 있고, 다문화청소년 개인적으로도 부정적 자아상을 내면화시키는 
등 바람직하지 못한 결과가 나타날 수 있다(NYPI, 2020). 이에 본 연구는 다문화청소년의 의사소통 능력을 특정적 편견없이 살펴보 고자, 학급변화, 지역규모, 그리고 문화 · 언어적 배경 요인에 따른 다문화청소년의 사회적 의사소통 능력(Social communication competence, SCC) 프로파일을 개별 문항과 공감과 소통능력, SCC 종 합점수 평가결과로 구분하여 분석하였다.

사회적 의사소통 능력(SCC)은 사회적 상호작용에서 자신과 타 인의 요구와 기대를 충족하는 지식과 기술, 행동을 의미하는 사회 성(Social competence; Goldstein, Kaczmarek, \& English, 2002), 언 어에 대한 이해와 표현 능력을 갖춘 능숙한 의사소통 능력, 그리고 언어 및 인지적 지식을 기반으로 한 화용 규칙 적용 능력 등을 포함 한다(Crago \& Ericks-Brophy, 1994; Crago \& Cole, 1991; Cummings, 2009, 2014; Hwa-Froelich, 2015; Müller, 2000). 청소년기에 이러한 SCC를 잘 갖추기 위해서는 앞에서 언급한 대로 SCC를 구 성하는 사회성과 의사소통 능력, 화용언어 능력과 같은 세가지 요 소들이 잘 발달되어 있어야 한다. 이를 구체적으로 살펴보면 첫째,
또래 또는 성인과의 상호작용에서 사회성이 발달되어 있어야 하며, 둘째, 상대의 질문에 적절하게 응답하거나 대화 주제를 유지하면서 번갈아 가며 이야기할 수 있는 능숙한 의사소통 기술 능력을 갖추 고 있어야 하고, 마지막으로 상대의 모호한 표현이나 비언어적 행 동에 대해 암묵적인 의도를 추론하고, 상대에 맞게 자신의 발화를 수정하여 표현할 수 있는 마음이론 및 화용 능력이 발달해야 한다.

한국교육개발원(Korean Education Development Institute, $\mathrm{KEDI})$ 은 국내 청소년이 미래지향적인 인재로써 성장하고 있는지 를 확인하고, 한국교육과정에 대한 평가와 개선을 목표로 한국교 육종단연구(Korean Educational Longitudinal Study, KELS; $\mathrm{KEDI}, 2020$ )를 2005년 이후부터 1차와 2차로 나누어 진행하고 있 다. KELS 2차 패널인 '2013 한국교육종단연구(2013 KELS)'는 2016 년(중학교 2학년)과 2018년(고등학교 1학년)에 국내 청소년 대상 전 국표집을 통해 사회성, 마음이론, 의사소통 기술, 메타의사소통과 같은 하위 문항들로 구성된 '의사소통 역량'을 조사하여 데이터를 공개하였다. 그리고 이번 연구는 공개된 ' 2013 KELS 의사소통 역

Table 1. Overview of KELS

\begin{tabular}{|c|c|c|c|}
\hline \multicolumn{4}{|c|}{ KELS } \\
\hline & \multicolumn{2}{|r|}{ Duration } & \multirow{2}{*}{ Key factors } \\
\hline & The 1st Panel (2005-2020 yr) & The 2nd Panel (2013-2030 yr) & \\
\hline Stage 1 & $\begin{array}{c}\text { From 1st grade of middle school to high } \\
\text { school graduation } \\
2005-2010 \\
\text { (6 years, every one year) }\end{array}$ & $\begin{array}{l}\text { From 5th grade of elementary } \\
\text { school to high school graduation } \\
2013-2020 \\
\text { (8 years, every one year) }\end{array}$ & $\begin{array}{l}\text { - Cognitive and non-cognitive achievements } \\
\text { - Cognitive and non-cognitive development } \\
\text { - Educational support for families } \\
\text { - Education level of secondary schools } \\
\text { - School life and friendship } \\
\text { - High school entrance process } \\
\text { - Analysis of educational policy effects, etc. }\end{array}$ \\
\hline Stage 2 & $\begin{array}{l}\text { From high school graduation to } \\
28 \text { years old } \\
2011-2020 \\
\text { (Uni } 1 \text { \& 2, Every } 1 \text { Year; }\end{array}$ & $\begin{array}{r}\text { From high school graduation to } \\
28 \text { years old } \\
2021-2030 \\
\text { Uni4, Uni4+2, Uni4+4, Every } 2 \text { Years) }\end{array}$ & $\begin{array}{l}\text { - Cognitive and non-cognitive achievement } \\
\text { - Going to college and living in college } \\
\text { - After secondary education } \\
\text { - Education experience and level } \\
\text { - Career and job acquisition, etc. }\end{array}$ \\
\hline \multicolumn{4}{|c|}{ Annual survey tool of 2013 KELS (2013-2018) } \\
\hline Year & Grade & Students & Parents \\
\hline 2013 & E5 & $\begin{array}{l}\text { - Student questionnaire } \\
\text { - Basic ability test (Korean, English, Mathematics) }\end{array}$ & Parent questionnaire \\
\hline 2014 & E6 & - Student questionnaire & Parent questionnaire \\
\hline 2015 & M1 & - Basic ability test (Korean, English, Mathematics) & \\
\hline 2017 & M3 & - Learner Characteristic Survey & \\
\hline 2016 & M2 & - Student questionnaire & Parent questionnaire \\
\hline 2018 & $\mathrm{H} 1$ & $\begin{array}{l}\text { - Basic ability test (Korean, English, Mathematics) } \\
\text { - Student Competencies Survey }\end{array}$ & \\
\hline
\end{tabular}

$\mathrm{E} 5=5$ th grade in elementary school; $\mathrm{E} 6=6$ th grade in elementary school; $\mathrm{M} 1=1$ st grade in middle school; $\mathrm{M} 2=2 \mathrm{nd}$ grade in middle school; $\mathrm{M} 3=3 \mathrm{rd}$ grade in middle school; $\mathrm{H1}=1$ st grade in high school; $\mathrm{KELS}=$ Korean Educational Longitudinal Study; Uni = University.

Data released so far in 2020. 
량’ 조사문항이 SCC에 포함되는 것을 확인하고, $2013 \mathrm{KELS} \mathrm{‘의사}$ 소통 역량'을 SCC로 정의하여 분석하였다(Table 1).

학생의 교육적 성장에 대한 국가적 관심이 주로 이전에는 학업성 취도와 같은 인지적 영역에 치중해 왔지만 최근 들어 전인적 측면 에서 학습의 질을 측정해야 한다는 인식이 확산되고 있으며, 현 단 계의 성취도를 넘어서 미래 사회를 살아가는 데 필요한 역량에 대 한 관심으로 옮겨 가기 시작하였다. 2000년대 초반에 OECD가 주 도한 역량중심의 교육프로젝트(DeSeCo Project; OECD, 2002)와 2012년 가을부터 시작된 유네스코의 Learning Metrics 프로젝트 (Learning Metrics Task Force, LMTF, 2013)는 교육적 성과에 대한 관심을 미래지향적이며 전인적 측면으로 확장하고 있다(Kang et al., 2013). 이에 우리나라에서도 국제적 수준에 상응하는 학생역량 향상을 목표로 하는 교육과정 개정이 2015년에 이루어졌다(KEDI, 2020). '2015년 개정 교육과정'에서는 다양한 학생역량 중 '사회적 의사소통 능력(SCC)'을 의사소통 역량으로 구분하여 타인과 원만 한 관계를 형성하고 협력하는데 필요한 공감과 소통을 포괄하는 역량으로 정의하였다. 그리고 SCC를 미래 사회가 요구하는 인재의 기초 의사소통 역량으로 보고 있다. 아동기에서 성인기로 진입하는 청소년 시기의 학생들은 자신의 자아정체성을 정립하고 자신에게 적합한 진로를 탐색하는 등 성인생활을 적극적으로 준비해야 하는 시기이다. 그러므로 청소년기 학생들이 전인적 측면에서 어떠한 의 사소통 발달 양상을 보이고 있으며, 미래 시민으로서 필요한 SCC 를 어느정도 구비하고 있는지를 확인하는 것은 중요하다.

청소년기는 유아와 아동 시기를 거쳐 성인으로 성장하는 기간으 로 육체적으로, 감성적으로, 정서적으로 매우 활발하게 발달하면 서도 불안정한 시기로 발달심리학에서는 13-19세까지를 청소년기 또는 사춘기라고 부르고(Dolgin, 2018; Marotz \& Allen, 2016), 한 국의 학년으로 구분하여 보았을 때는 일반적으로 중1-고3 정도의 시기를 지칭한다. 청소년기 변화에 있어 가장 큰 변화는 육체적으 로 2차 성징이 찾아오면서 생리학적으로 호르몬의 변화가 찾아온 다는 것이다. 그러므로 청소년 시기에는 본인이 자신을 보기에도 큰 변화가 있기 때문에 가장 많은 심리적 혼란을 겪으며 자의식 (self-consciousness), 자기 정체성(self-identity)과 같은 자아에 대한 개념이 증가한다(Dolgin, 2018; Steinberg, 2020). 그리고 언어발달 에 있어 아동기와 큰 차이를 보이는 측면은 추상적인 언어를 이해 하고, 언어논리를 이용하여 문제해결을 할 수 있다는 점이다. 그리 고 성인과 유사한 난해한 사고에 대한 의사소통도 가능하며 농담, 빈정거림, 비유와 같은 고차원의 화용언어를 이해하고 사용할 수 있다는 것이다(Nippold, 2007).

그리고 청소년기의 또래관계는 그 이전의 시기와는 다른 의미와
양상을 보인다. 청소년들은 아동기때와는 달리 또래 친구와 스마트 폰으로 음성통화나 소셜 네트워크 서비스(Social Network Service, $\mathrm{SNS}$ )를 이용하여 더 많은 시간을 소통하면서 또래 사회를 형성한 다. Raffaelli와 Duckett (1989)은 또래 친구와의 소통은 특히 남학 생보다는 여학생에게 더욱 두드러지게 나타나지만, 부모 또는 가족 과 이야기하는 시간이 성별에 따라 변화하는 것은 아니라고 하였 다. 그리고 청소년들은 부모 또는 가족과 소통하는 시간이 또래와 소통하는 시간과 큰 차이를 보이지는 않았지만, 흥미로운 점은 또 래 친구와의 소통은 가족 구성원과의 소통과는 질적으로 다른 부 분으로 가족 구성원과의 소통으로 대체될 수 없는 새로운 측면의 소통이라고 하였다(Raffaelli \& Duckett, 1989). 청소년들은 이성친 구 문제나 음악과 축제와 같은 또래 문화와 관련된 주제에 대해 가 족 구성원보다는 또래 친구들과 더 쉽게 이야기 나눌 수 있다고 하 였다. 반대로 가족 구성원과의 대화 주제는 중요한 판단이 필요한 문제 또는 심각한 진학 문제에 대해서 이야기하는 것으로 나타났 다. 즉, 청소년들은 또래 친구와 가족으로부터 다른 형태의 지지를 받으며, 문제의 심각성과 상황에 따라 또래 친구, 가족 구성원, 또는 둘 모두(또래, 가족)와 소통하는 것으로 보였다. 그리고 청소년기에 사회적 의사소통 발달이 적절하게 발달하기 위해서는 또래, 가족 모두와 소통할 수 있는 환경이 주어져야 한다고 보았다(Rawlins, 1992). 하지만 청소년기에 또래 친구 관계가 특히 중요한 것은, 청소 년들은 또래 친구와의 의사소통을 통해 스스로에 대한 정체성, 신 념, 포부를 생각해보게 된다. 그리고 또래 친구와의 정서적인 유대 를 형성하면서 청소년들은 우정이라는 특별한 종류의 정서적 관계 를 형성하면서 자신만의 세계와는 다른 서로의 관계라는 맥락 이 해가 발달한다(Goldstein et al., 2002).

의사소통 능력에 대한 성별 차이를 종단으로 살펴본 결과 남학생 과 여학생은 대화 능력에서는 차이가 없는 것으로 나타났다(Larson \& Mckinley, 1998). 다만 남학생들은 대화 상대자에게 농담이 나 유머를 사용해서 대화상대자를 더 즐겁게 하는 경향이 여학생 들보다 더 유의미하게 많았을 뿐, 은유적 표현의 언어 사용이나 화 제 전환, 질문하기와 같은 다양한 대화 능력은 여학생들과 유사하 였다고 한다(Larson \& Mckinley, 1998). 즉, 의사소통에 있어 성별 차이는 의사소통 방식(communication style)의 차이일 뿐 능력 차 이는 아니었다. 성별 의사소통 방식의 차이는 남. 여에 따라 세상을 바라보는 시각 차이가 있기 때문이라고 한다(Nippold, 2007; Tannen, 1990). 일반적으로 남성은 세상을 위계적으로 보기 때문에 대 화를 관계에 있어 우의를 정하거나 유지하는 조건으로 보지만, 여 성의 경우는 세상을 개인 간의 연결로 바라보기 때문에 관계와 친 밀성을 대화의 조건으로 본다고 한다. 그렇기 때문에 여성이 남성 
에 비하여 좀 더 대화 상대자에게 호응을 해주고 긍정적인 반응을 보여주지만, 남성의 경우는 여성과는 달리 대화 상대자의 주제를 전환하거나 끼어들기와같은 행동을 더 많이 보인다고 한다. 하지만 이러한 성별에 따른 의사소통 방식 차이는 아주 근소한 차이일 뿐 이라고 하였다(Leaper \& Robnett, 2011; McCormick \& Scherer, 2018).

국내 다문화가구는 30 만 6,995 가구로 추정되며 결혼이민자가구 가 대부분(85.7\%)을 차지하고, 기타 귀화자가구는 $14.3 \%$ (4만 4026 가구)로 조사됐다. 그리고 10 년 이상 국내 거주 외국인은 $60.6 \%$ 로 장기 정착자가 많았다. 2015년에 비하면 10년 이상 국내 거주자는 $12.7 \%$ 포인트나 늘어났다(Ministry of Gender Equality and Family, 2019). 통계 자료를 통해 알 수 있듯이 결혼이민자들의 유입으로 국내 외국인 수는 많아진 상황이다. 이러한 현상은 한국 정부가 결 혼이민자 여성을 국가정책적으로 받아들인 1990년 후반부터 시작 되었다(Cha \& Ryu, 2019). 그리고 결혼이민자 이외 다양한 유형의 국내 유입 외국인이 늘면서 국내외국인의 출생국도 다양해지고 있 다. 국내는 한국인 남성과 결혼하여 한국에 입국하는 중국 또는 동 남아 여성 결혼이민자(2015년 기준 275,527명; Ministry of Gender Equality and Family, 2019), 한국에서의 일자리를 찾아 입국한 중 국 및 서남아시아 노동자(2019년 기준 287,895명; Statistics Korea, 2020 ), 북한에서 남한으로 이주한 북한이탈주민(2016년 기준 29,830명; Ministry of Gender Equality and Family, 2019), 한국 대 학에 유학 온 중국인 유학생(2019년 기준 71,067명; Ministry of Education, 2020a) 및 베트남 유학생(2019년 기준 37,426명; Ministry of Education, 2020a), 한국에 상주하는 미국 군인들(2019년 기 준 32,900명; Statistics Korea, 2020), 국내 학교에 취업해 있는 외국 인 강사 및 교수(2019년 기준 24,234명; Statistics Korea, 2020) 등이 주로 국내 다문화사회를 구성하고 있다.

한국사회에 다문화적 배경을 지닌 사람들이 증가하게 됨에 따라 다문화가정의 자녀도 점차 증가하고 있다. 교육부 기준 2019년도 다문화학생의 수는 137,225 명으로 이는 전체 학생수(5,461,614명) 의 2.51\%를 차지한다(Ministry of Education, 2020b). 다문화학생 수는 매년 증가되어 왔고, 최근 들어 증가하고 있는 중도입국청소년 과 외국인근로자 자녀의 추세를 고려하면 향후 다문화배경을 지닌 청소년의 수는 더욱 증가할 것으로 예측되고 있다(Ministry of Education, 2020b). 다문화청소년 중 현재 가장 높은 비율을 차지하는 집단은 국내에서 출생하고 성장한 국제결혼가정의 자녀로, 2019년 교육부 기준에 의하면 108,069 명이며 그 특성이 어머니 국적 배경 에 따라 매우 다양하다. 다문화학생의 거주 지역 비율을 구분하여 보았을 때는 경기, 서울에 가장 많이 재학하고 있으며, 전체 학생 대
비 다문화학생 비율은 전남, 충남이 가장 높은 것으로 나타났다. 다 문화학생 중 중도입국 · 외국인학생 비중은 서울(39\%), 경기(32\%) 가 높으며, 국내 출생 다문화학생 비중은 전남· 전북(95\%)이 높은 것으로 나타났다(Ministry of Education, 2020b).

한국의 다문화는 1990년 이후로 그 역사가 30년 정도로 짧으며, 전체 인구의 $3.1 \%$ 라는 적은 수의 집단이지만 다양한 문화적 배경 을 가지고 있다. 다문화청소년패널조사(NYPI, 2020)에 의하면 국 내 다문화가정 내 어머니의 결혼 전 국적은 크게 총 7 개(중국: 한족, 중국: 조선족, 베트남, 필리핀, 일본, 태국, 기타)로 구분 가능하며 이 중 일본(501명, 34.82\%)이 가장 많았고 다음으로는 필리핀(374명, 25.99\%), 조선족 중국인(287명, 19.94\%), 한족 중국인(110명, 7.64\%) 순이었다. 나머지는 기타(77명, 5.35\%), 태국(54명, 3.75\%), 베트남 (36명, 2.50\%) 순이었다(Lee, 2020). 소수 국내 다문화청소년들은 이러한 다양한 문화적 배경이라는 차이에도 불구하고 몇 가지 공 통된 특성을 보인다. 첫째, 다문화청소년의 대부분(85.7\%)은 한국 에서 태어나 자랐으며, 대부분(88.7\%)이 한국어만을 사용하고 있 었다(Kim et al., 2016). 둘째, 이들의 외모가 국내 일반 청소년과는 다르기 때문에 쉽게 구별 가능하며, 또래 친구들로부터 편견과 적 대감의 대상이 되기 쉽고, 이러한 가능성에 대해 청소년들은 이미 잘 알고 있다(Ministry of Gender Equality and Family, 2019). 셋째, 사회경제적으로 불리한 조건에 놓인 다문화가정의 비율이 일반 단 일문화가정에 비하여 높은 편이다(Yang, 2013).

다양한 집단이 국내 다문화사회를 구성하면서 다문화집단에 대 한 사회제도와 소통의 문제가 국가적 화두가 되었다. 국내에서는 2008년에 다문화가족 구성원이 안정적인 가족생활을 영위할 수 있 도록 다문화가족에 대한 삶의 질 향상과 사회통합에 이바지함을 목 적으로 '다문화가족지원법(Support for Multicultural Families Act)' 을 제정하였으며, 2017년 이후로 계속적인 개정을 통해 추가적 내용 을 보완해가고 있다(Reliable Ministry of Government Legislation, 2020). 2015년에 출범한 여성가족부 한국건강가정진흥원을 통해 다 문화가족 지원센터에서 다문화가정 외국인 부모와 만 12 세 이하 다 문화가정 아동에게는 언어발달 서비스를 지원하고 있다. 그리고 다 문화청소년에 대해서는 다문화가정 실태조사와 다문화청소년패널 을 이용한 조사가 진행되고 있다. 다문화가정 실태조사는 여성가족 부에서 3년마다 실시(현재까지 2009, 2012, 2015, 2018년 조사되었 음)하는 것으로 실태조사를 통해 다문화청소년에 대한 사회정서와 환경 조사가 이루어지고 있다. 한국청소년정책연구원은 2011년에 1,625 다문화가구를 다문화청소년패널로 구성하여 패널이 24세 성 인이 되는 2025년까지 다문화청소년의 학업과 사회정서발달, 환경 요인 등에 대한 조사를 진행하고 있다(Yang \& Kim, 2018). 그리고 
다문화가정 및 이주배경 청소년의 한국사회 정착과 학습 능력 및 직 업역량 향상을 위해서는 무지개청소년센터를 운영하고 있다. 즉, 국 내 다문화사회는 제도 및 사회지원을 통해 변화를 시도하고 있다.

국내 다문화가정에 대한 정책적 그리고 사회적 지원, 실태조사 이외에 성공적인 다문화사회를 이끌기 위해서는 다문화가정과 단 일문화가정 간의 원활한 사회적 소통과 통합이 요구된다. 사회적 의사소통 문제는 종교, 사회, 민족(인종), 교육 등의 배경이 다른 개 인이 모인 조직에서 자연스럽게 발생하는 것으로 보이기 때문이다 (Claudia, 2017; Clouet, 2013). 그리고 다문화사회를 이해하기 위해 서는 다른 문화배경을 가진 사람과의 상호작용을 통해 상대방의 사회적 언어를 이해하고, 문화간 의사소통 속에서 다른 문화배경 을 가진 사람들의 사회적 인식, 생각 패턴 및 행동을 이해하고 교류 하여 문화간 의사소통 문제를 줄여가는 것이 요구된다. 즉 물리적, 사회적 통합 이외에 다문화사회 공동체는 사회구성원에 대한 문화 적 이해와 공감, 소통하는 사회적 의사소통 능력이 요구된다. 왜냐 하면 사회적 의사소통은 맥락을 기반으로 하는 상호작용으로서, 의사소통에 참여하는 개인들은 자신 및 타인의 감정과 의도에 대 한 사실과 개념, 그리고 사회인지를 통해 사람과 세상에 대한 지식 과 경험을 동시에 접속하고 처리하면서 역동적인 사회적 소통을 하 고 있기 때문이다. 그러므로 소수 문화에 속하는 다문화청소년이 사회적 의사소통을 원활하게 진행하기 위해서는 자신과 타인의 감 정(feeling)에 대해 인지하고 이러한 감정이 어떻게 행위로 연결되 어 나타나는지, 그리고 사건이나 개인의 행동이 어떻게 감정을 유 발하는 지를 이해하는 사회 인지능력이 중요한 사회적 의사소통 능력의 구성요소이다(Muma, 1991). 그리고 이러한 사회인지 능력 은 화용 능력의 인지적 요소로서 포함된다(Capone \& Mey, 2015; Cummings, 2009, 2014, 2015).

자폐범주성장애(Autism Spectrum Disorder, ASD), 언어장애 (Language Impairment, LI), 주의력결핍/과잉행동장애(Attention Deficit Disorder with or without the Hyperactivity component, $\mathrm{ADD} / \mathrm{ADHD})$, 사회 · 정서장애(Social-Emotional Disorders, SED) 와 같은 의사소통장애 문제로 사회적 의사소통 장애를 보이는 대 상자도 있다. 하지만 일반 집단으로 생각해 보았을 때는, 일반적으 로 사회적 의사소통 방식과 능력은 가정내 사회경제적 수준(socioeconomic status, SES)과 문화에 의해 주로 영향을 받는다(Cummings, 2009, 2014, 2015). 빈곤가정 아동들은 지체된 언어 능력을 보이는 경우가 많은데, 특히 어휘와 복잡한 구문에 대한 표현과 발 달에 있어 일반가정과는 차이를 보인다(Dollaghan et al., 1999; Hart \& Risley, 1995; Hoff, 2003; Huttenlocher, Vasilyeva, Cymerman, \& Levine, 2002). 그리고 이들 아동들은 주류 문화에서 이해
하고 받아들여지지 않는 행동과 비공식적인 담화 형태(neighborhood discourse style)를 학습하여 주류 문화의 화용법칙과 사회적 의사소통 방식을 거의 학습하지 못했을 가능성이 높다. 그러므로 표준화된 언어 검사에서 낮은 수행 수준을 보이는 경향이 나타난 다(Hart \& Risley, 1995; Qi, Kaiser, Milan, \& Hancock, 2006; Qi, Kaiser, Milan, McLean, \& Hancock, 2003). 주류 사회에서 이들 대 상자들의 화용 의사소통 형태는 오해를 일으키기 쉽고, 갈등의 소 재가 될 수 있으며, 학교에서 정학 또는 퇴학을 당하는 부정적인 사 회적 결과를 낳기도 한다(Delpit, 1995; Harry, 1992; Kalyanpur \& Harry, 1999; Terrell \& Terrell, 1996). 사회적 의사소통에 있어 낮은 언어 능력과 제한된 언어에 대한 노출, 그리고 주류와는 다른 화용 언어에 대한 노출은 사회적 의사소통 발달과 학업 수행에 부정적 인 영향을 미친다.

문화는 부모세대가 자녀에게 사회적 행동과 의사소통 행동을 가 르치는 양육과정을 통해 다음세대로 전달된다. 그리고 문화적 가 치는 미디어, 정책, 법률, 철학, 학교와 같은 교육기관을 통해 전달되 며, 모든 문화에는 가치를 두는 행동이 있다(Hwa-Froelich, 2015; Lane, 2010; Reed, 2012; Vygotsky, 1986; Wertsch, 1985). 서구 문화 에서는 개인이 다른 사회 구성원과 독립적으로 행동하는 것에 더 가치를 두고 있으며, 아시아 문화권에서는 사회 구성원과 상호 의 존적으로 행동하는 것에 더 가치를 부여한다(Greenfield \& Cocking, 1994; Hofstede, 2001; Hofstede, Pederson, \& Hofstede, 2002). Triandis (1995)는 이러한 두가지의 구분된 가치에 대해 개인주의 또는 집단주의로 표현하였다. 개인주의의 가치는 타인과 다르고 독 립적인 것을 가장 좋은 것으로 보며, 집단주의는 타인과 유사하게 행동하고 상호의존적으로 사고하는 것을 더 좋게 평가한다. 이러 한 문화적 체계는 부모가 자녀와 상호작용할 때 보이는 상호작용 행동과 목표에 영향을 미친다. 그러므로 다양한 문화적 배경을 가 진 다문화가정 자녀는 주류사회의 사회적 의사소통을 다르게 해석 하거나 일반적인 반응과는 다르게 반응을 할 지도 모른다.

현재 국내 다문화청소년을 대상으로 사회적 의시소통 능력(SCC) 을 평가하여 분석한 연구는 거의 없었다. 국내 다문화청소년을 대 상으로 진행된 의사소통 연구는 대부분 또래와 부모와의 의사소 통 수준이 다문화청소년의 사회 - 정서 - 행동문제와 어떠한 관련을 보이는 지를 관찰하는 연구들로 양적으로 의사소통을 어느 정도 하는지에 주 초점이 맞추어 있다(Kim \& Hong, 2017; Kim, 2013; Kim \& Lee, 2020; Cha \& Ryu, 2019). 그런데 앞에서 살펴보았듯이 청소년시기에는 또래 친구관계를 통해 SCC가 활발하게 발달한다. 그리고 다문화가정 청소년은 일반가정 단일문화 청소년에 비하여 소수 집단이며, 사회경제적 취약계층 비율이 높다는 점, 문화적 배 
경이 다양하게 다르다는 점 등의 특성이 보인다. 이러한 차이는 다 문화가정 청소년이 일반가정 단일문화청소년들과는 다른 SCC 발 달에 영향을 미쳤을 것으로 예측된다. 이에 이번 연구는 '2013 KELS' 에서 국내 청소년을 대상으로 진행된 '의사소통 역량(사회적 의사 소통 능력)’ 조사 공개데이터 중 다문화청소년의 SCC를 문화집단 (다문화청소년, 단일문화청소년)별 학급(중학교 2학년, 고등학교 1 학년)과 거주지역규모(특별시, 대도시, 중·소도시, 읍·면지역)에 따 라 프로파일을 분석하였다. 그리고 이후 다문화청소년의 문화적 배 경(출생지역, 사용언어)에 따른 SCC를 문항 프로파일 분석을 통해 살펴보았다. 구체적인 연구문제는 다음과 같다.

연구문제 1. 문화집단별(다문화청소년, 단일문화청소년) SCC 프 로파일은 학급변화(중학교 2학년, 고등학교 1학년)에 따라 차이가 있는가?

연구문제 2. 문화집단별(다문화청소년, 단일문화청소년) SCC 프로파일은 거주지역규모(특별시, 대도시, 중·소도시, 읍·면지역) 에 따라차이가 있는가?

연구문제 3. 다문화청소년은 출생지역(한국, 외국)과 사용언어 (한국말, 어머니 또는 아버지 나라 말, 한국말과 어머니 또는 아버 지 나라 모두 사용)에 따라서 SCC 프로파일 차이를 보이는가?

\section{연구방법}

\section{연구참여자}

'한국교육종단연구(KELS; Kim et al., 2016)'는 한국 교육에 관 한 종단적 자료를 구축하여 교육정책의 수립 및 집행과 성과평가 를 위한 기초자료를 수집하고 이를 분석하는 연구이다. 현재 KELS 는 1 차와 2 차 패널로 구분하여 진행되고 있다. 1 차 패널연구는 중학 교 1학년 대상자가 만 28세가 되는 시점(2005-2020년)까지 16년간 종단으로 진행되었다. 그리고 2 차 패널연구는 초등학교 5학년 대상 자가 만 28세가 되는 시점(2013-2030년)까지 약 18년간 종단으로 진행될 예정이다(Table 1).

1 차와 2 차 패널 모두 조사기간에 있어 대상자 연령별 두가지 단 계로 구분하였다. 제 1 단계 조사기간은 초.중등교육 단계로 설정하 였다. 즉, 1 차 패널연구에서는 중학교 1학년 그리고 2 차 패널연구에 서는 초등학교 5 학년 대상자들이 고등학교 3 학년이 되는 시점까지 를 1 단계로 보았다. 1 단계는 학생들이 학교 교육 및 또래 활동을 통 하여 성장하고 발달하는 핵심적인 청소년기 기간으로, 1 단계의 주 요 조사 내용은 대상자들의 인지 및 비인지적 성취와 발달, 가정내 교육적 지원, 학교생활과 또래 관계, 학생역량, 고등학교 입학 준비 과정 등이다. 2 단계에 있어서는 1 차와 2 차 패널연구 모두 패널 대상
자들이 고등학교를 졸업한 시점에서 28 세까지 성인기를 대상으로 하였다. 2 단계의 주요 조사 내용은 대학 입학과 대학생활, 그리고 대학 졸업 후직업활동 등이다(Table 1).

이번 연구는 학생역량 조사가 진행된 2차 KELS 패널연구 1단계 (청소년기)를 분석하였다. 2020년 12월 현재까지 KELS 2차 패널 공 개용 데이터는 초등학교 5학년(2013년 1차년도)에서 고등학교 1학 년(2018년 6차년도)까지의 종단 데이터가 공개적으로 제공되고 있 다(Table 1). 이중 의사소통 학생역량(사회적 의사소통 능력)은 2016년(중학교 2학년, 4차년도)과 2018년(고등학교 1학년, 6차년) 도 대상자에게만 조사가 진행되었다. 이에 이번 연구는 '2차 패널 1 단계' 대상자들이 중학교 2학년과 고등학교 1학년이었을 때의 데이 터를 분석하였다(Table 1).

패널 대상자 선정에 있어, 2 차 패널(2013 KELS) 조사 연구는 학 생 표본을 추출하기 위하여 층화군집무선추출법(stratified cluster random sampling)을 적용하였다. 즉, 학생 표본의 추출을 위하여 먼저 전국을 16 개 시·도와 지역규모에 따라 층(stratum)으로 나누 고, 각 층으로부터 군집(cluster)인 표본 학교를 추출하고, 마지막 단 계에서 추출된 학교로부터 표본 학생을 추출하였다. 그 결과 2차 패널 '한국교육종단연구 2013'은 2013년에 242개 초등학교 5학년 에 재학하는 7,324명의 학생을 표본으로 하고 있다. 표본 학교는 서 울에서 36 개교, 대도시에서 49 개교, 중 - 소도시에서 80 개교, 읍.면 지역에서 77 개교 등 총 242 개 학교가 추출되었으며, 이들 학교는 설 립유형별로는 국·공립이 232 개교, 사립이 10 개였다. 그리고 그 중 소규모 학교가 49 개교였다(Table 2).

2013년 1차년도 패널 원표본은 7,324명이었으며 이중 149 명은 다 문화가정이라고 응답하였으며, 5,832명은 일반가정, 1,343 명의 응 답은 결측치(무응답, 응답오류)에 속하였다. 2016년 10월 4차년도 학생 변동 사항을 파악한 결과 표본 탈락, 해외 이주. 이민 및 유학, 유예, 전지훈련, 장기입원 등 조사불가, 연락두절 및 추적불가 학생 이 551명 발생하여, 4차년도 조사 대상자는 총 6,773명으로 원표본 대비 $92.48 \%$ 였다. 4 차년도 대상자 6,773 명 중 의사소통 역량 설문 에 응답한 대상자는 6,669명(98.46\%)이었으며, 이중 135명(2\%)은 다문화가정이라고 응답하였다. 그리고 2018년 11월에 6차년도 조 사 대상 학생은 변동 사항을 파악한 결과 표본 탈락자, 해외 이주. 이민 및 유학, 유예, 전지훈련, 장기입원, 연락두절 및 추적불가 학 생 875명을 제외한 총 6,449명으로 원표본 대비 88.05\%였다. 6차년 도 대상자 6,449 명 중 의사소통 역량 설문에 응답한 대상자는 6,263 명(97.12\%)이었으며, 이중 다문화가정이라고 응답한 대상자 는 123명(1.9\%)이었다(Table 3).

2013년 1차년도 부모설문지 조사에서 문화적 배경(다문화가정 
Table 2. First panel population and sample size of $2013 \mathrm{KELS}$

\begin{tabular}{|c|c|c|c|c|c|c|}
\hline & \multicolumn{3}{|c|}{ School } & \multicolumn{3}{|c|}{ E5 } \\
\hline & Pop & Sam & Ratio & Pop & Sam & Ratio \\
\hline \multicolumn{7}{|l|}{ Region } \\
\hline Special city (Seoul) & 591 & 36 & 6.09 & 88,345 & 1,374 & 1.56 \\
\hline Metropolitan city & 1,066 & 49 & 4.60 & 132,017 & 1,735 & 1.31 \\
\hline Small and medium-sized cities & 1,648 & 80 & 4.75 & 221,110 & 2,762 & 1.25 \\
\hline Town (Eup/Myeon Area) & 2,168 & 77 & 3.55 & 82,645 & 1,453 & 1.76 \\
\hline \multicolumn{7}{|l|}{ School type } \\
\hline National \& Public & 5,434 & 232 & 4.27 & 517,345 & 6,967 & 1.34 \\
\hline Private & 75 & 10 & 13.33 & 6,772 & 366 & 5.40 \\
\hline Total & 5,509 & 242 & 4.39 & 524,117 & 7,324 & 1.40 \\
\hline
\end{tabular}

E5=5th grade in elementary school; KELS=Korean Educational Longitudinal Study; Pop=Population; Sam=Sampling.

Table 3. Cultural background of the 1st, 4th, and 6th 2013 KELS

\begin{tabular}{|c|c|c|c|c|c|c|c|c|}
\hline \multicolumn{9}{|c|}{ Cultural group } \\
\hline \multirow{2}{*}{ Year } & \multirow{2}{*}{ Grade (Age) } & & \multirow{2}{*}{ Subjects (\%) } & \multirow{2}{*}{$\begin{array}{c}\text { CC Respondents } \\
(\%)\end{array}$} & \multicolumn{4}{|c|}{ Cultural group (\%) } \\
\hline & & & & & Multi & Mono & Total & Missing \\
\hline 2013 & $\mathrm{E} 5(11)$ & & $7,324(100.0)$ & No & $149(2.49)$ & $5,832(97.51)$ & $5,981(100)$ & 1,343 \\
\hline 2016 & M2 (14) & & $6,773(92.48)$ & 6,669 (91.06) & $135(2.47)$ & $5,320(97.53)$ & $5,455(100)$ & 1,214 \\
\hline 2018 & $\mathrm{H} 1$ (16) & & $6,449(88.05)$ & $6,263(85.51)$ & $123(2.40)$ & $4,997(97.60)$ & $5,120(100)$ & 1,143 \\
\hline \multicolumn{9}{|c|}{ Cultural background } \\
\hline \multirow{2}{*}{ Year } & \multirow{2}{*}{ Grade (Age) } & \multicolumn{3}{|c|}{ Country of birth $(\%)$} & \multicolumn{4}{|c|}{ Language choice (\%) } \\
\hline & & Korea & Others & Total & Korean & Foreign & Both & Total \\
\hline 2013 & $\mathrm{E} 5(11)$ & $120(85.71)$ & $20(14.29)$ & $140(100)$ & $118(83.69)$ & $3(2.13)$ & $20(14.18)$ & $141(100)$ \\
\hline 2016 & M2 (14) & $110(87.30)$ & $16(12.70)$ & $126(100)$ & $107(84.25)$ & $2(1.57)$ & $18(14.17)$ & $127(100)$ \\
\hline 2018 & $\mathrm{H} 1$ (16) & 98 (85.96) & $16(14.03)$ & $114(100)$ & $96(83.49)$ & $2(1.74)$ & $17(14.78)$ & $115(100)$ \\
\hline
\end{tabular}

$\mathrm{CC}=$ Communication competence; $\mathrm{E}=$ Elementary school; $\mathrm{H}=$ High school; $\mathrm{M}=$ Middle school; Mono=mono-cultural backgrounds; Multi=Multi cultural backgrounds; KELS=Korean Educational Longitudinal Study; Respondents=Respondents of communication competency questionnaire.

여부) 문항에 응답한 대상자 5,981명 중 다문화가정이라고 응답한 대상자는 149 명 $(2.49 \%)$ 이었으며, 이중 9명을 제외한 140 명 중 출생 국가가 한국인 경우는 120 명이었고 국외인 경우는 20 명이었다. 그 리고 다문화청소년 118 명은 한국어를 주로 사용하였으며, 3 명은 엄 마나 아빠나라의 말, 20 명은 한국어와 외국어 모두를 사용하는 것 으로 나타났다(Table 3).

2013년 1차년도 부모설문지 조사에서 문화적 배경(다문화가정 여부, 자녀의 출생국가, 자녀가 사용하는 언어) 문항에 응답한 대상 자 5,981명 중 2016년 4차년도 학생역량 조사에 참여한 대상자는 135 명이었다. 그리고 출생국가 문항 응답자 126 명 중 대상자 청소 년의 출생국가가 한국인 경우는 110 명이었고 국외인 경우는 16 명 이었다. 사용언어 응답자 127 명 대상자 중 107 명은 한국어를 주로 사용하였으며, 2 명은 엄마나 아빠나라의 말, 18 명은 한국어와 외국 어 모두를 사용하는 것으로 나타났다. 1 차년도 부모설문지 조사에
서 문화적 배경 문항에 응답한 대상자 중 2018년 6차년도 학생역량 조사에 참여한 대상자는 5,120 명이었으며 이중 123 명은 다문화가 정이었다. 그리고 청소년의 출생국가에 응답한 114 명 중 출생국이 한국인 경우는 98 명, 국외인 경우는 16 명이었다. 사용언어에 대한 조사결과에서는 응답자 115 명 대상자 중 96 명은 한국어를 주로 사 용하였으며, 2 명은 엄마나 아빠나라의 말, 17 명은 한국어와 외국어 모두를 사용하는 것으로 나타났다(Table 3).

\section{연구과제}

\section{사회적 의사소통 능력(Social Communication Competence, SCC)}

'2013 KELS' 학생역량 조사는 'KEDI 학생역량 조사 연구' 학생 용 역량 조사 설문지를 활용하였다(Namgung et al., 2016). 학생역 량 조사는 6 가지 역량(자기관리 역량, 지식정보처리 역량, 창의적 사고 역량, 심미적 감성 역량, 의사소통 역량, 공동체 역량)에 대해 
조사를 진행하였으며, 이번 연구는 학생역량 조사 문항 중 ‘의사소 통 역량’만을 따로 구분하여 분석하였다. 의사소통 역량은 공감과 소통 각각 5 개 문항씩 총 10 개 문항으로 구성되어 있다. 10 개 개별 문항을 하위 측정 영역으로 분석하여 보았을 때는 사회성, 인지적 마음이론, 의사소통 기술, 정서적 마음이론, 메타의사소통을 측정 하는 것으로 구분되었는데, 이는 '사회적 의사소통 능력(SCC)'의 하위 범주에 속하는 것이었다(Dennis et al., 2013; Hwa-Froelich, 2015) (Table 4). SCC 문항에 대한 점수화는 전혀 그렇지 않다(1점) 와 매우 그렇다(5 점)와 같은 5점 리커트 척도(5-point Likert-type scale)로 구성되어 있다(Table 4).

2015년 KEDI의 학생역량 조사 타당도 분석 결과 의사소통 역량 문항별 평균은 3.47-4.17이었으며, 확인적 요인분석 결과 적합도 지 수는 RMSEA .05이하, CFI와 TLI는 .90 이상인 것으로 나타났다. 이는 측정 모형의 적합도가 매우 타당하다는 것을 나타낸다. 의사 소통 역량의 각 요인들과 해당 문항들의 표준화 계수 추정치는 공 감의 경우 .49-.78이고, 소통의 경우 .65-.80으로 나타났다. 공감과 소통 각 요인은 5 개 문항으로 구성되며, 신뢰도 계수는 공감 .807 , 소통 .856의 높은 신뢰도를 보이는 것으로 나타나, 각 요인별 측정 문항들 간에 내적일관성이 있는 것으로 분석되었다(Namgung et al., 2015).

\section{연구절차}

현재 ‘2013 KELS' 학생역량 조사 연구는 한국교육개발원 홈페이 지를 통해 연구용 데이터를 제공하고 있고, 'KEDI 학생역량 조사
연구' 데이터는 비공개이며 한국교육개발원 연구보고서(http:// www.kedi.re.kr)를 통해서 제시하고 있다. 이번 연구는 '2013 KELS' 4 차와 6 차 연구 데이터 중 의사소통 역량을 분석하여 청소년의 SCC를 살펴보았다. SCC는 공감과 소통 각각 5 문항, 총 10 개 문항으 로 구성되어 있는데 개별 문항에 따라 측정하는 영역에 있어 차이 를 보이고 있다(Table 4). 이에 국내 문화집단별 청소년들의 사회적 의사소통 능력을 분석함에 있어 개별 문항에 따른 SCC 평가의 차 이를 SCC 프로파일 분석을 통해 살펴보았다. 프로파일 분석은 집 단의 특성을 좀더 면밀히 관찰하기 위한 것으로 개별 문항에 대한 분석에 용이하다. 그리고 본 연구는 $2013 \mathrm{KELS}$ 데이터를 이용한 것 으로 $2013 \mathrm{KELS}$ 의 연구절차를 구체적으로 살펴보면 다음과 같다.

\section{조사 방법}

KEDI '2013 KELS'는 학생을 최고 18년간 추적 조사하는 것으로 2013년 1차년도 설문 연구 참여에 동의한 학생과 학부모만을 연구 대상자로 포함하였다. 조사 설문지는 총 4 종으로 학생 설문지, 학생 역량 조사지(의사소통 역량 포함), 학부모 설문지, 학교 조사지 등 이다. 4차년도 조사는 2016년 10월 4주부터 11월 4주까지 전국 1,200 여개 중학교에서, 그리고 6차년도 조사는 2018년 10월 4주부 터 11월 4주까지 전국 고등학교에서 실시하여 자료를 수집하였다 (Namgung et al., 2018).

조사 표본에 대한 조사와 추적 관리를 위해 '2013 KELS'는 설문 조사와 조사 결과 데이터 구축 업무를 전문조사업체를 통해 실시 하였다. 그리고 효율적인 조사 대상 관리를 위해 조사 위탁기관이

Table 4. Social communication competence (SCC) subscale division

\begin{tabular}{|c|c|c|c|}
\hline Scale & Sub-areas & No. of items & Range of score \\
\hline \multicolumn{4}{|l|}{ SCC } \\
\hline E1. Trying to understand a friend's feelings & Social competence & 1 & $1-5$ \\
\hline E2. I can understand my friend's mind well & Cognitive ToM & 1 & $1-5$ \\
\hline E3. Listening to friend's concerns well & Communication skill & 1 & $1-5$ \\
\hline E4. feeling good when my friend gets a compliment & Affective ToM & 1 & $1-5$ \\
\hline E5. When a friend feels bad, I feel bad, too & Affective ToM & 1 & $1-5$ \\
\hline C6. Thinking about what to say in conversation & Metacommunication & 1 & $1-5$ \\
\hline C7. Choosing easy and accurate words for the listener & Metacommunication & 1 & $1-5$ \\
\hline C8. Giving examples for listeners & Metacommunication & 1 & $1-5$ \\
\hline C9. Knowing one's thought from facial expression and gestures & Metacommunication & 1 & $1-5$ \\
\hline C10. Showing that are listening well & Metacommunication & 1 & $1-5$ \\
\hline Empathy (Total score from E1 to E5) & & 5 & $5-25$ \\
\hline Communication (Total score from C6 to C10) & & 5 & $5-25$ \\
\hline SCC Total (Comprehensive score of empathy and communication) & & 10 & $10-50$ \\
\hline \multicolumn{4}{|c|}{ 5-point Likert-type scale } \\
\hline Strongly disagree (1) & Disagree (2) Neutral (3) Agree (4) & Strongly agree (5) & \\
\hline
\end{tabular}

$\mathrm{C}=$ Communication competence; $\mathrm{E}=$ Empathy competence; $\mathrm{SCC}=$ Social communication competence; $\mathrm{ToM}=$ Theory of Mind. 
직접 표본 학생을 관리하는 방식이 아닌 조사 대상 학교의 연구협 력교사를 통한 조사 및 관리를 진행하였다. 성공적인 조사를 수행 하기 위해서 1,200 여개 이상 학교에 대한 실사 관리를 위한 통합관 리 시스템을 마련하여 운영하였다. 이중 설문지 회수의 경우, 학부 모 설문지는 학교에서 회송용 봉투와 함께 가정에 보내어 실시한 후 학교에서 수합하였으며, 학생용 설문지(학생역량 조사지 포함) 는 '방과 후 시간'에 학교 및 가정에서 이루어질 수 있도록 지도하였 다. 그리고 학교접촉, 배송물품, 조사현황, 회송결과, 자료입력까지 통합하여 관리하며 안전한 조사 자료 배·회송을 위해서 전용 박 스/봉투를 이용하고 전담 운송 업체(우체국 택배)를 지정하여 운영 하였다. 그리고 배·회송 시 학교별 배·회송 과정을 조사 용역업체 연구원이 $100 \%$ 검수하였다(Kim et al., 2016).

\section{표본 유지 및 관리}

'2013 KELS' 조사 대상의 중학교 진학 사항을 파악하기 위해서 1 차년도 패널 구축 학생 수에서 조사 철회와 유예 학생을 제외한 학생 7,225명을 대상으로 시.도 교육청의 협조를 통해서 7월말에 서 8 월에 걸쳐 해당 중학교 2 학년의 진급 여부와 전학 여부를 확인 하였다. 아울러 9월 19일부터 23일까지 연구협력교사 확정 후 조사 의 효율성을 고려하고, 자료의 보안 및 분실 방지를 위해 웹 프로그 램을 이용하여 진급 사항과 전학 여부를 다시 조사하였다. 진급 학 생의 현재 학급 및 번호까지 확인하여 본조사의 효율성을 제고하 였다. 조사 대상자가 미성년이기 때문에 패널 관리는 학부모를 중 심으로 진행하였다. 조사 진행 이전 및 진행 중에는 조사 목적, 대 상 등 조사 개요 중심의 정보를, 조사 완료 이후에는 응답한 데이터 에 대한 정보를 담은 소식지를 발송하여 학부모와 학생이 조사에 대한 긍정적인 이미지를 갖게 하였다(Kim et al., 2016).

\section{자료분석 및 통계처리}

수집된 data는 IBM SPSS 25.0과 Excel (Office 365)을 이용하여 분석하였다. 그리고 연구문제 분석에 앞서 문화집단(다문화청소 년, 단일문화청소년) 간 성별, 거주지역규모, 학교설립유형 예측변 수에 대한 차이검증을 위해 교차분석( $\chi^{2}$ test)을 실시하였다.

연구문제 1 은 문화집단별 사회적 의사소통 능력을 비교하여 살 펴보았다. '2013 KELS'의 2016년과 2018년 의사소통 역량 조사내용 을 13 가지 측정변수(사회적 의사소통 능력 개별 10 문항, 공감, 소통 능력, 종합점수)로 구분하여 문화집단별 학급변화(중학교 2학년, 고등학교 1학년)에 따른 차이를 다변량분석(MANOVAs)을 통해 살펴보았다. 연구문제 2 는 지역규모(특별시, 대도시, 중·소도시, 읍. 면지역)에 따른 종속변수(사회적 의사소통 능력 개별 10 문항, 공감,
소통능력, 종합점수)의 차이에 대해 문화집단별 학급연령(중2, 고1) 에 따라 구분하여 다변량분석(MANOVAs)을 실시하였다. 그리고 연구문제 3 은 다문화청소년의 출생지역(한국, 외국)과 사용언어(한 국말, 어머니 또는 아버지 나라 말, 한국말과 어머니 또는 아버지 나 라 모두 사용)에 따라서 SCC 점수와 SCC 개별 문항 평가 평균에서 차이가 있는지를 다변량분석(MANOVAs)을 통해 살펴보았다.

\section{연구결과}

\section{교차분석 결과}

2013 KELS 예측변수인 문화집단(다문화청소년, 단일문화청소

Table 5. Difference of gender, school-type, and residential size by cultural group

\begin{tabular}{|c|c|c|c|}
\hline \multirow{2}{*}{ M2 } & Multi & Mono & \multirow{2}{*}{$N(\%)$} \\
\hline & $N(\%)$ & $N(\%)$ & \\
\hline \multicolumn{4}{|l|}{ Gender } \\
\hline Male & $67(2.55)$ & 2,563 (97.45) & $2,630(100.0)$ \\
\hline Female & $68(2.41)$ & 2,757 (96.59) & $2,825(100.0)$ \\
\hline Total & $135(2.47)$ & $5,320(97.53)$ & $5,455(100.0)$ \\
\hline \multicolumn{4}{|c|}{$\chi^{2}<1(\mathrm{df}=1, n s)$} \\
\hline \multicolumn{4}{|l|}{ School-type } \\
\hline National \& Public & $107(2.43)$ & 4,297 (97.57) & $4,404(100.0)$ \\
\hline Private & $28(2.67)$ & 1,022 (97.33) & $1,050(100.0)$ \\
\hline Total & $135(2.48)$ & $5,319(97.52)$ & $5,454(100.0)$ \\
\hline \multicolumn{4}{|c|}{$\chi^{2}<1(\mathrm{df}=1, n s)$} \\
\hline \multicolumn{4}{|l|}{ Regional size } \\
\hline \multicolumn{4}{|l|}{ M2 } \\
\hline Special (\%) & $16(11.85)$ & $947(17.80)$ & $963(17.66)$ \\
\hline Metro & $27(20.00)$ & 1,286 (24.18) & $1,313(24.07)$ \\
\hline SM & $43(31.85)$ & 2,199 (41.34) & 2,242 (41.11) \\
\hline Town & $49(36.30)$ & 887 (16.68) & 936 (17.16) \\
\hline \multirow[t]{2}{*}{ Total } & $135(100.0)$ & $5,319(100.0)$ & $5,454(100.0)$ \\
\hline & \multicolumn{3}{|c|}{$\chi^{2}=36.01^{* * *}(\mathrm{df}=3, p=.000)$} \\
\hline \multicolumn{4}{|l|}{$\mathrm{H} 1$} \\
\hline Special (\%) & 14 (11.38) & 870 (17.48) & 884 (17.33) \\
\hline Metro & 25 (20.33) & 1,221 (24.53) & $1,246(24.43)$ \\
\hline SM & 45 (36.59) & 2,065 (41.48) & $2,110(41.36)$ \\
\hline Town & 39 (31.71) & 822 (16.51) & 861 (16.88) \\
\hline \multirow[t]{2}{*}{ Total } & $123(100.0)$ & $4,978(100.0)$ & $5,101(100.0)$ \\
\hline & \multicolumn{3}{|c|}{$\chi^{2}=20.56^{* * *}(\mathrm{df}=3, p=.000)$} \\
\hline
\end{tabular}

$\mathrm{H} 1=1$ st grade in high school; $\mathrm{M} 2=2 \mathrm{nd}$ grade in middle school; Special=special city; Metro=metropolitan city; SM=small and medium-sized cities; Town=Eup/ Myeon area; $\mathrm{ns}=$ nonsignificant.

${ }^{* * *} p<.001$ 
년), 학급(중학교 2학년, 고등학교 1학년), 성별(남학생, 여학생), 거 주지역규모(특별시, 대도시, 중·소도시, 읍·면지역), 학교설립유형 (국공립, 사립), 출생배경(한국, 외국), 사용언어(한국어, 부모나라 말인 외국어, 모두)에 대한 기술은 교차분석을 실시하여 제시하였 다(Tables 5, 6). 그 결과는 다음과 같다.

중학교 2학년 문화집단(다문화청소년, 단일문화청소년)에 따라 성별(남학생, 여학생)과 거주지역규모(특별시, 대도시, 중·소도시, 읍·면지역), 학교설립유형(국공립, 사립) 차이를 분석하였다. 분석 결과 다문화청소년의 성별 비율은 남:여 $=67: 68$ 명이었으며, 단일문 화청소년은 남:여 $=2,563: 2,757$ 명이었으며 문화집단에 따라 성별 은 차이가 없었다 $\left(\chi^{2}<1, \mathrm{df}=1, n s\right)$. 그리고 문화집단별 등교하는 학 교설립유형 분석 결과 다문화청소년은 국 · 공립:사립 $=107: 28$ 명이 었으며, 단일문화청소년은 국·공립:사립 $=4,297: 1,022$ 명이었으며, 문화집단별 학교설립유형의 교차분석 결과는 유의미한 차이가 없 었다 $\left(\chi^{2}<1, \mathrm{df}=1, n s\right)$. 하지만 거주지역규모에는 유의미한 차이가 나타났다 $\left(\chi^{2}=36.01^{* *}, \mathrm{df}=3, p=.000\right)$. 다문화청소년의 경우는 읍.면지역과 중·소도시에 거주하는 비율( 92 명, $68.15 \%)$ 이 높았으 나, 단일문화청소년은 중·소도시와 광역대도시에 거주하는 비율 $(3,485$ 명, $65.52 \%)$ 이 높은 것으로 나타났다. 그리고 이러한 차이는 중학교 2학년 대상자들이 고등학교 1학년으로 학급이 변화했을 때도 동일한 현상이었다 $\left(\chi^{2}=20.56^{* * *}, \mathrm{df}=3, p=.000\right)$. 즉, 대상 청 소년들은 학급변화에 따라(중학교 2학년, 고등학교 1학년) 거주지 역의 규모 변화는 없었다(Table 5).

그리고 다문화청소년만을 대상으로 출생배경과 거주지역 간의 교차분석 결과는 유의미하지 않았다. 즉, 출생배경이 한국 또는 외 국인지와는 상관없이 대부분의 다문화청소년은 읍. 면지역과 중 . 소도시에 거주하였다. 그리고 이러한 현상은 학급이 변화해도 동 일하였다(중학교 2학년: $\chi^{2}=3.45, \mathrm{df}=3, p=.328$ /고등학교 1학년: $\left.\chi^{2}=1.33, \mathrm{df}=3, p=.722\right)$. 이에 대해 구체적으로 살펴보면 다음과 같다(Table 6). 중학교 2 학년 다문화청소년 135 명 중 출생배경과 거 주지역 문항에 응답한 대상자는 총 126 명으로 9 명의 응답은 무응 답과 응답오류와 같은 결측 값이었다. 한국에서 태어난 110 명 다문 화청소년은 대부분 읍.면지역(45명, 40.91\%)에 거주하였으며, 다음 으로는 중·소도시(29명, 26.36\%)와 광역대도시(22명, $20.00 \%)$ 와 서 울특별시(14명, $12.73 \%)$ 에 거주하였다. 부모나라에서 출생한 다문 화청소년은 총 16 명이었다. 부모나라인 외국에서 출생한 다문화청 소년은 대부분은 중·소도시(7명, 43.75\%)에 거주하였으며, 다음으 로는 광역대도시(4명, $25.00 \%$ ), 읍.면지역(3명, 18.75\%)과 서울특별 시(2명, $12.50 \%)$ 에 거주하였다. 고등학교 1학년 다문화청소년 135 명 중 출생배경과 거주지역 문항에 응답한 대상자는 총 114 명으로,

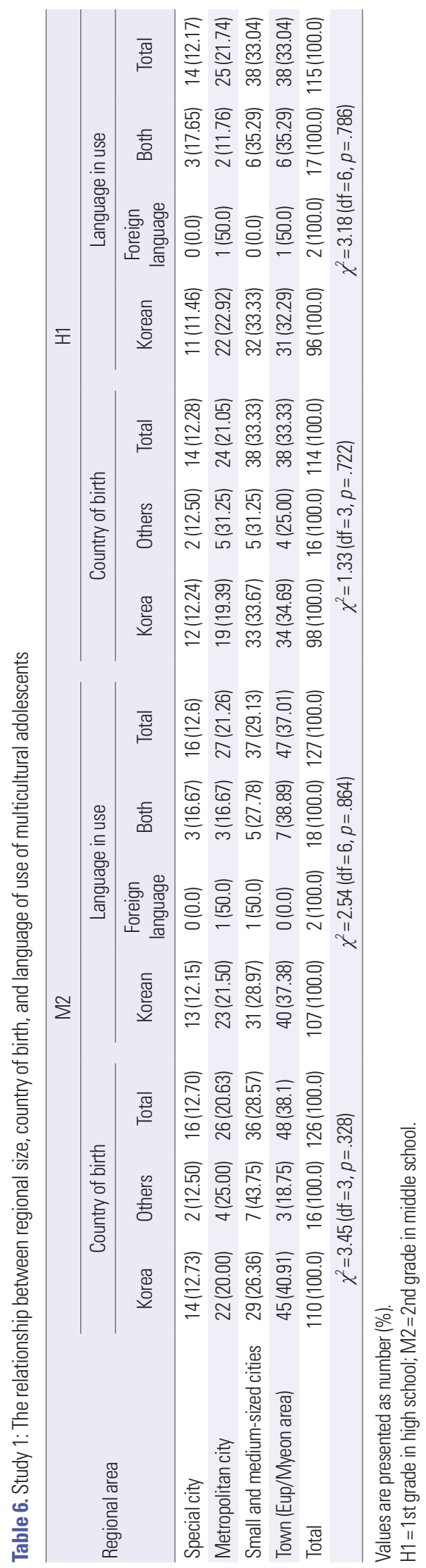

https://doi.org/10.12963/csd.21791 
21 명의 응답은 무응답과 응답오류와 같은 결측 값이었다. 한국에서 태어난 98명 다문화청소년은 대부분 읍 · 면지역(34명, 34.69\%)과 중 · 소도시(33명, 33.67\%)에 거주하였으며 이외 광역대도시(19명, $19.39 \%)$ 와 서울특별시(12명, 12.24\%) 순으로 거주하였다. 부모나라 에서 출생한 다문화청소년 총 16 명 중 대부분은 중 · 소도시(5명, $31.25 \%)$ 와 광역대도시(5명, 31.25\%)에 거주하였으며, 다음으로는 읍 - 면지역(4명, 25.00\%)과 서울특별시(2명, $12.50 \%)$ 순으로 거주하 였다(Table 6).

또한 다문화청소년만을 대상으로 사용언어와 거주지역 간의 교 차분석 결과는 유의미하지 않았다. 즉, 주로 사용하는 언어가 한국 어 또는 부모나라의 말인 외국어, 한국어와 외국어 모두를 사용하 는 것과는 상관없이 대부분의 다문화청소년은 읍 - 면지역과 중 . 소도시에 거주하였다. 그리고 이러한 현상은 학급이 변화해도 동 일하였다(중학교 2학년: $\chi^{2}=2.54, \mathrm{df}=6, p=.864$ )/고등학교 1학년: $\left.\chi^{2}=3.18, \mathrm{df}=6, p=.786\right)$. 이에 대해 구체적으로 살펴보면 다음과 같다(Table 6). 중학교 2 학년 다문화청소년 135 명 중 사용언어와 거 주지역 문항에 응답한 대상자는 총 127 명으로 8 명의 응답은 무응 답과 응답오류와 같은 결측 값이었다. 한국어만을 사용하는 107 명 다문화청소년은 읍 - 면지역(40명, 37.38\%)에 거주하였으며, 다음으 로는 중 · 소도시(31명, 28.97\%)와 광역대도시(23명, 21.50\%)와 서울 특별시(13명, 12.15\%)에 거주하였다. 부모나라 말인 외국어만을 사 용하는 다문화청소년은 총 2 명이었으며, 광역대도시와 중소도시 에 각각 1 명씩 거주하고 있었다. 그리고 한국어와 부모나라말 모두 를 사용하는 다문화청소년은 총 18 명이었다. 이들은 읍.면지역(7명, $38.89 \%)$, 중 - 소도시(5명, 27.78\%)와 광역대도시(3명, 16.67\%), 서울 특별시(3명, $16.67 \%)$ 순으로 거주하였다. 고등학교 1학년 다문화청 소년 135 명 중 사용언어와 거주지역 문항에 응답한 대상자는 총 115 명으로 20 명의 응답은 무응답과 응답오류와 같은 결측 값이었 다. 한국어만을 사용하는 96 명 다문화청소년은 대부분 읍. 면지역 (34명, 34.69\%)과 중 · 소도시(33명, 33.67\%)에 거주하였으며 이외 광역대도시(19명, 19.39\%)와 서울특별시(12명, 12.24\%) 순으로 거주 하였다. 한국어만을 사용하는 다문화청소년 총 96 명 중 대부분은 중 · 소도시(32명, 33.33\%)와 읍.면지역(31명, 32.29\%)에 거주하였으 며, 다음으로는 광역대도시(22명, 22.92)와 서울특별시(11명, 11.46\%) 순으로 거주하였다. 부모나라 말인 외국어만을 사용하는 다문화 청소년은 총 2 명이었으며, 광역대도시와 읍.면지역에 각각 1 명씩 거 주하고 있었다. 그리고 한국어와 부모나라말 모두를 사용하는 다 문화청소년은 총 17 명이었다. 이들은 읍. 면지역(6명, $35.29 \%$ )과 중. 소도시(6명, 35.29\%), 광역대도시(2명, $11.76 \%$ ), 서울특별시(3명, $17.65 \%$ ) 순으로 거주하였다(Table 6).

\section{연구결과 1. 문화집단별 청소년의 SCC 프로파일 분석}

문화집단(다문화청소년, 단일문화청소년)에 따라 SCC 점수(공 감, 소통능력, SCC 종합점수)와 SCC 개별 문항 10개(E1-5, C6-10) 의 평가가 차이가 있는지를 학급(중학교 2학년, 고등학교 1학년)별 로 구분하여 분석하여 보았다(Table 7).

분석 결과 중학교 2학년의 경우, 다문화청소년보다 단일문화청 소년의 공감능력(Empathy: $\left.F_{(1,5,436)}=4.65^{*}, p<.05\right)$, 소통능력(Com: $\left.F_{(1,5,435)}=6.67^{*}, p<.01\right), \mathrm{SCC}$ 종합점수 $\left(\right.$ Total: $\left.F_{(1,5,427)}=6.68^{*}, p<.01\right)$ 가 더 높게 나타났다. 문화집단별(다문화청소년, 단일문화청소년) 유의미한 차이가 있는 SCC 문항은 E1 (친구의 기분을 이해하려고 노력한다; $F_{(1,5,443)}=5.94^{*}, p<.05$ ), $\mathrm{E} 3$ (친구들의 고민을 잘 들어준다; $\left.F_{(1,5,443)}=9.47^{* *}, p<.005\right), \mathrm{C} 6$ (대화를 할 때 어떻게 말해야 할지 미리 생각하고 말한다; $F_{(1,5,443)}=4.75^{\star}, p<.05$ ), $\mathrm{C} 8$ (듣는 사람이 잘 이해 할 수 있도록 쉽고 정확한 말을 골라 이야기한다; $F_{(1,5,441)}=10.25^{\star * *}$, $p<.001$ ), $\mathrm{C} 10$ (대화할 때 이야기를 잘 듣고 있다는 것을 말이나몸짓 으로 보여준다; $\left.F_{(1,5,443)}=4.69^{*}, p<.05\right)$ 등의 5 가지였다.

고등학교 1 학년의 SCC 평가결과, 다문화청소년과 단일문화청소 년의 공감능력(Empathy: $\left.F_{(1,5101)}<1, \mathrm{~ns}\right)$ 은 유의미한 차이가 없었다. 소통능력 $\left(\mathrm{Com}: F_{(1,5099)}=5.44^{*}, p<.05\right)$ 은 유의수준 .05수준에서 유 의미한 차이를 보였고, SCC 종합점수(Total: $F_{(1,5095)}=3.38^{\dagger}, p=$ .066) 문화집단별 차이는 유의미한 경향성만을 보였다. 그리고 문 화집단별(다문화청소년, 단일문화청소년) 유의미한 차이가 있는 SCC 문항은 C7 (듣는 사람이 이해할 수 있도록 쉽고 정확한 말을 골라 말한다; $F_{(1,5,103)}=5.23^{*}, p<.05$ ), $\mathrm{C} 8$ (듣는 사람이 이해할수 있 도록 예를 들어 설명한다; $\left.F_{(1,5,102)}=7.78^{* *}, p<.005\right)$ 등의 2 가지였다. 그리고 $\mathrm{E} 4$ (친구가 선생님께 칭찬을 받으면 나도 기분이 좋아진다; $F_{(1,5,103)}=3.39^{\dagger}, p=.065$ ), $\mathrm{C} 9$ (상대방의 표정과 몸짓을 살피면서 속 마음을 이해한다; $F_{(1,5,103)}=3.48^{\dagger}, p=.062$ ), $\mathrm{C} 10$ (대화할 때 이야기 를 잘 듣고 있다는 것을 말이나 몸짓으로 보여준다; $F_{(1,5,103)}=3.16^{\dagger}$, $p=.076$ ) 문항은 .05 이하 수준에서는 유의미한 차이가 없었지만 유 의미한 경향성이 보였다.

그리고 문화집단의 학급변화에 따른 SCC는 E1 (친구의 기분을 이해하려고 노력한다; $\left.F_{(1,10,548)}=2.76, p=.096\right) 1$ 개 문항에서만 유 의미한 경향성이 있었을 뿐 나머지 9개 문항과 3 가지 SCC 점수에 서(공감능력, 소통능력, SCC 종합점수)는 유의미한 차이가 없었다. 즉, 다문화청소년은 학급이 상승하면서 '친구의 기분을 이해하려 고 노력하는 부분'에 대한 평가가 높아졌지만 단일문화집단은 학 급변화와 상관없이 평균 4.27 (그렇다와 매우 그렇다의 중간) 정도 의 높은 평가를 유지하고 있었다. 


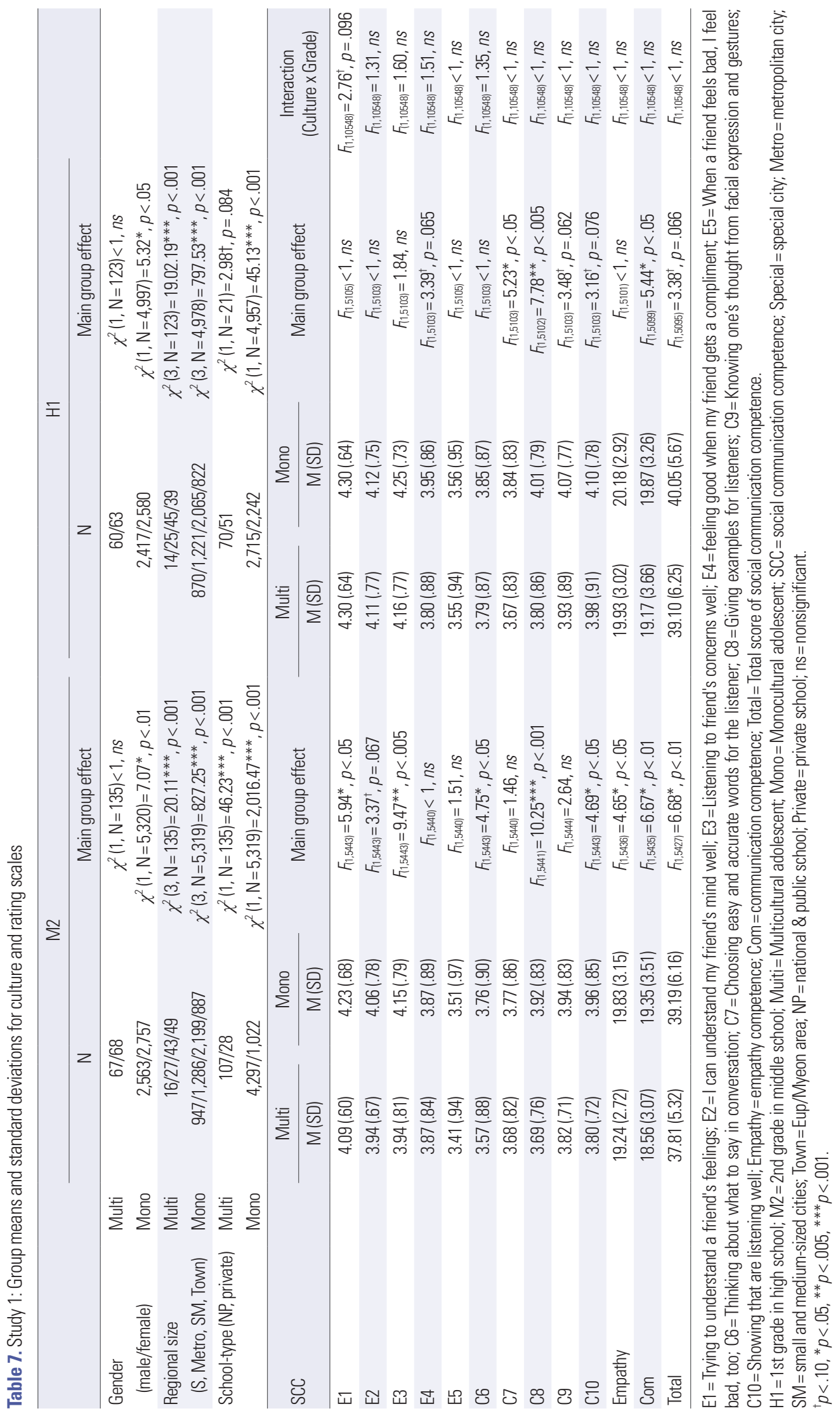




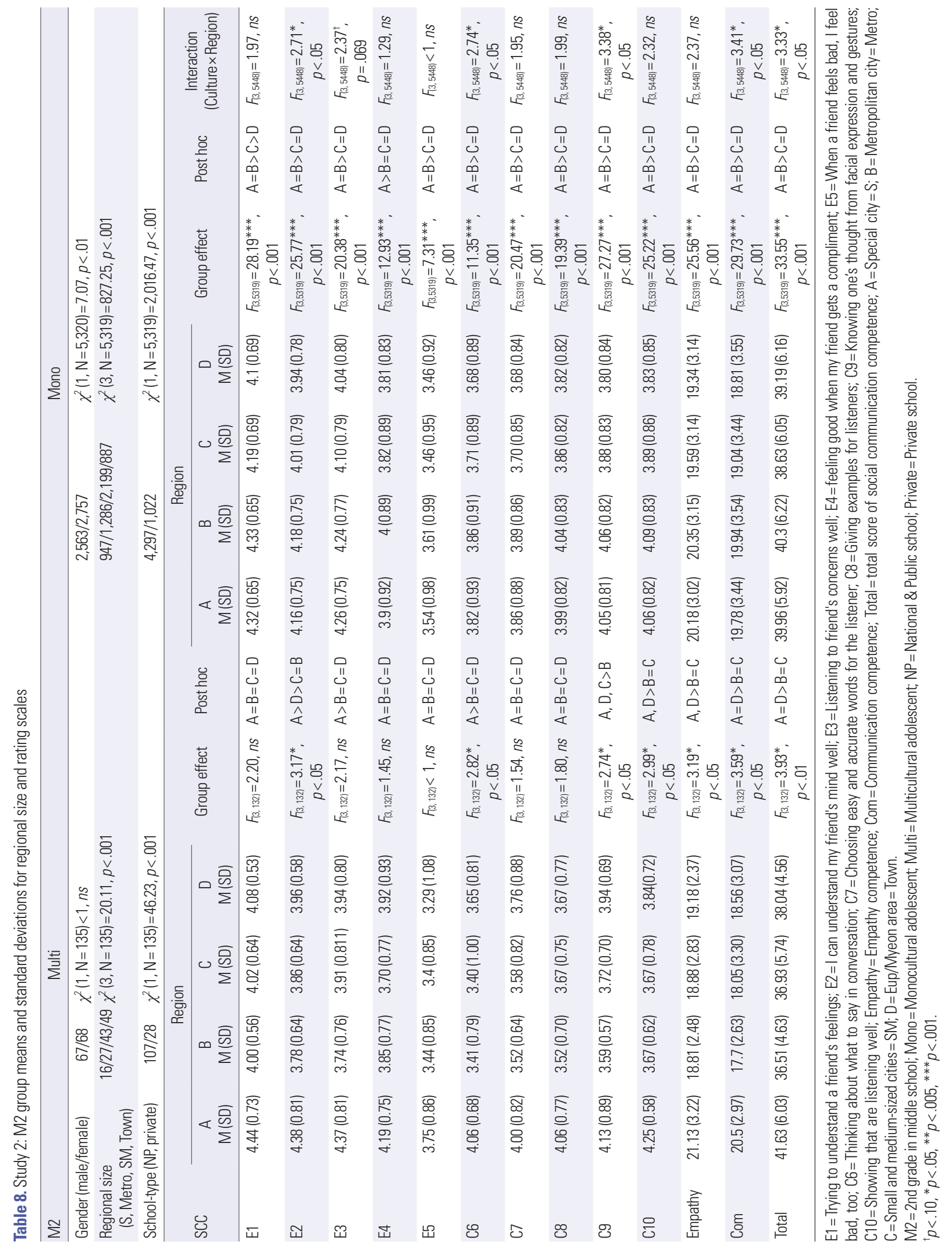




\section{연구결과 2. 문화집단과 거주 지역규모에 따른 SCC 프로파일 분석}

문화집단에 따라 거주하는지역은 차이가 있었다 $\left(\chi^{2}=36.01, \mathrm{df}=3\right.$, $p=.000 ; \chi^{2}=20.56, \mathrm{df}=3, p=.000$ ). 조사에 참여한 중학교 2 학년 다문 화청소년 135명중 49명(39.3\%)은 읍.면지역에 그리고 43명(31.85\%) 은 중·소도시에 거주하여 전체의 $71.15 \%$ 가 특별시와 대도시 외곽 지역에 거주하는 것으로 나타났다. 그리고 다문화청소년 집단과는 다르게 단일문화청소년은 중소도시와 대도시에 $65 \%$ 이상이 거주 하고 다음으로 서울특별시에 $17.48 \%$ 가 거주하는 것으로 나타났다 (Table 5). 이러한 문화집단별 거주지역의 차이는 SCC에도 영향을 미치는지를 살펴보기 위하여 문화집단별 거주지역에 따라 SCC가 다르게 나타나고 있는지를 분석하여 보았다.

연구결과, 중학교 2학년 다문화청소년은 거주지역규모에 따라 공감능력(Empathy; $\left.F_{(3,132)}=3.19^{*}, p<.05\right)$, 소통능력 $\left(\mathrm{Com} ; F_{(3,132)}=\right.$ $\left.3.59^{*}, p<.05\right)$, SCC 종합점수(Total; $\left.F_{(3,132)}=3.93^{*}, p<.01\right)$ 에 차이 를 보였다. 그리고 개별 문항에 있어서는 $\mathrm{E} 2$ (친구의 생각과 감정을 잘 알 수 있다; $F_{(3,132)}=3.17^{*}, p<.05$ ), 66 (대화를 할 때 어떻게 말할 지 미리 생각하고 말한다; $F_{(3,132)}=2.82^{*}, p<.05$ ), C9 (상대방의 표정 과 몸짓을 살피면서 속마음을 이해한다; $\left.F_{(3,132)}=2.74^{*}, p<.05\right), \mathrm{C} 10$ (대화할 때 이야기를 잘 듣고 있다는 것을 말이나 몸짓으로 보여준 다; $\left.F_{(3,132)}=2.99^{*}, p<.05\right)$ 등 4 개 문항이 다문화청소년의 지역규모 에 따라 차이를 보였다. 다문화청소년과는 달리, 중학교 2학년 단일 문화청소년은 SCC 점수 3 가지와 모든 10 개 개별 SCC 문항이 거주 지역규모에 따라 유의미한 차이를 보이고 있었다. 단일문화청소년 은 서울특별시와 광역대도시 집단의 SCC 평가가 유사한 수준으로 높았으며 다음으로는 중. 소도시와읍.면지역 집단의 평가가 유사 한 수준으로 낮게 평가되었다(Table 8).

중학교 2학년의 문화집단별 거주규모에 따른 SCC 점수에 있어서 는 공감능력은 유의미한 차이가 없었으며, 소통능력 $\left(\mathrm{Com} ; F_{(3,5,48)}=\right.$ $3.41^{\star}, p<.05$ ), SCC 종합점수(Total; $F_{(3,5,448)}=3.33^{\star}, p<.05$ )는 유의 미한 차이를 보였다. 그리고 개별 문항 평가가 유의미하게 차이를 보 인 것은 $\mathrm{E} 2$ (친구의 생각과 감정을 잘 알 수 있다; $F_{(3,5,448)}=2.71^{\star}$, $p<.05)$, C6 (대화를 할 때 어떻게 말할지 미리 생각하고 말한다; $F_{(3,5,448)}=2.74^{*}, p<.05$ ), C9 (상대방의 표정과 몸짓을 살피면서 속마 음을 이해한다; $F_{(3,5,448)}=3.38^{\star}, p<.05$ ) 등 3 개 문항이었다. $\mathrm{E} 3$ (친구 들의 고민을 잘 들어준다; $\left.F_{(3,5,448)}=2.37^{\dagger}, p=.069\right)$ 문항은 유의미한 경향성이 나타났다(Table 8, Figure 1). 즉, 중학교 2학년 문화집단별 거주지역규모의 상호작용 분석 결과, '친구의 생각과 감정을 이해하 고, 대화를 할 때 미리 생각하면서 상대방의 표정과 몸짓으로 속마 음을 이해하면서 친구의 고민을 잘 들어주는 부분은 문화와 지역
에 따라차이를 보이는 문항이었다. 서울특별시에 거주하는 다문화 청소년은 단일문화청소년보다 SCC 점수와 개별 문항 평가가 높았 지만, 광역대도시에 거주하는 다문화청소년은 단일문화청소년보 다 SCC 점수가 많이 낮았다. 거주규모 집단별로만 구분하였을 때 는 가장 낮은 SCC 점수를 보인 집단은 광역대도시에 거주하는 다 문화청소년 집단이었으며, 다음으로는 중 - 소도시에 거주하는 다 문화청소년이었다. 그리고 읍 - 면 지역에 거주하는 청소년은 다문화 청소년과 단일문화청소년 간에 SCC 점수는 유사하였다(Figure 1).

고등학교 1학년이 되었을 때 다문화청소년은 지역규모에 따라 SCC 점수와 개별 문항에 대한 평가에 있어 유의미한 차이를 보이 지 않았다. 하지만 단일문화청소년은 고등학교 1학년이 되었을 때 도 중학교 2학년때처럼 지역규모에 따라 SCC 점수와 개별 문항 평 가 모든 측정변수에 유의미한 차이를 보이고 있다(Table 9). 특징적 인 것은 다문화청소년의 경우는 서울특별시 거주지역 집단의 SCC 점수와 개별 문항에 대한 평가가 중학교 2학년 때보다 평균점수가 낮아졌다. 그리고 이외 광역대도시, 중·소도시, 읍·면지역의 SCC 는 상승하였다. 그러므로 지역규모 집단의 차이가 중학교 2학년때 와는 달리 고등학교 1학년때는 유의미하지 않게 나타났다. 하지만 단일문화집단의 경우는 읍 · 면지역의 SCC 상승 정도가 가장 높기 는 하였지만 지역규모 집단의 SCC가 모두 상승하였다. 그러므로 단일문화청소년의 지역규모에 따른 SCC는 중학교 2 학년때와 유사 하게 차이를 보이는 것으로 나타났다(Table 9).

문화집단별 지역규모에 대한 SCC의 차이가 유의미하게 나타난 것은 유일하게 $\mathrm{E} 3$ (친구들의 고민을 잘 들어준다; $F_{(3,5,075)}=2.96$, $p<.05$ ). 1 개 문항이었다(Table 9, Figure 2). 다문화청소년 읍. 면지 역 집단이 '친구들의 고민을 잘 들어준다'고 평가한 것이 타 문화 . 지역규모 집단보다 월등히 높게 나타나면서 유의미한 상호작용 효 과가 나타났다.

\section{연구결과 3. 다문화청소년의 출생배경과 사용언어에 따른 $\mathrm{SCC}$ 프로파일 분석}

중학교 2학년 패널 대상 중 다문화청소년이면서 의사소통 역량 조사에 응답한 대상자는 124 명이었다. 이중 대부분 한국에서 출생 하였는데, 108 명은 한국에서 출생하였고 16 명은 외국에서 출생하 였다. 한국에서 출생한 다문화청소년 중 한국어만을 사용하는 청 소년은 94 명(87.04\%), 한국어와 부모나라말 모두를 사용하는 청소 년은 13명(12.4\%), 부모나라말만 사용하는 청소년은 1명(.92\%)이었 다. 그리고 외국에서 출생한 다문화청소년 16명 중 한국어만을 사 용하는 청소년은 11 명(68.75\%), 부모나라말만 사용하는 청소년은 1 명(6.25\%), 한국어와 부모나라말 모두를 사용하는 청소년은 4 명 


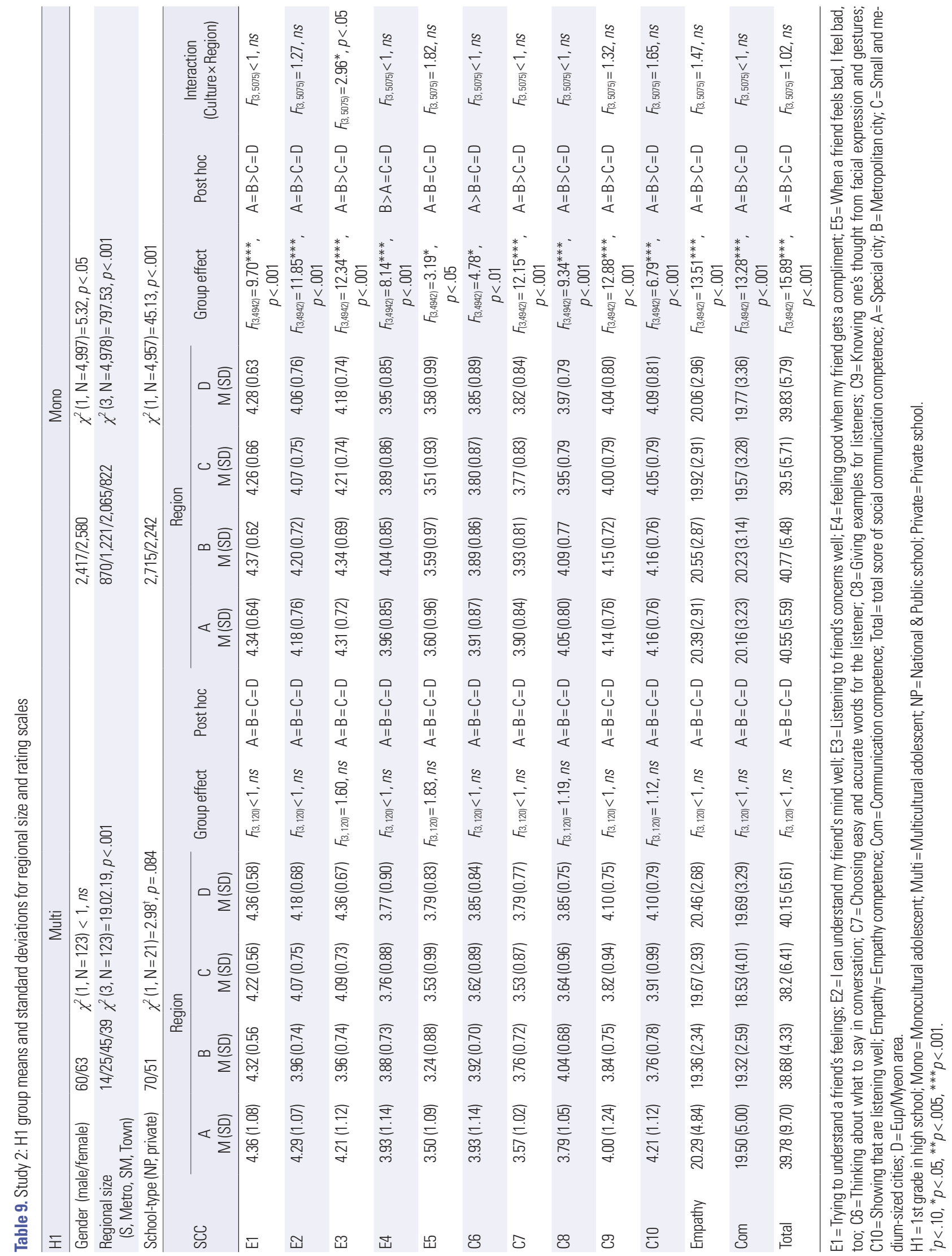


Eun Ju Lee - SCC profile analysis of Korean Multicultural Adolescents

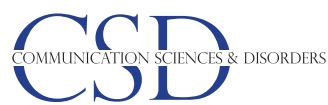

Table 10. Difference between country of birth and language of use

\begin{tabular}{|c|c|c|c|c|c|c|c|c|}
\hline & \multicolumn{4}{|c|}{ M2 } & \multicolumn{4}{|c|}{$\mathrm{H} 1$} \\
\hline & Korea & Foreign & Both & Total & Korean & Foreign & Both & Total \\
\hline Born in Korea & $94(87.04)$ & $1(.92)$ & $13(12.04)$ & $108(100.0)$ & $83(86.46)$ & $1(1.04)$ & $12(12.50)$ & $96(100.0)$ \\
\hline Born abroad & $11(68.75)$ & $1(6.25)$ & $4(25.00)$ & $16(100.0)$ & $11(68.75)$ & $1(6.25)$ & $4(25.00)$ & $16(100.0)$ \\
\hline \multirow[t]{2}{*}{ Total } & 105 (84.68) & $2(1.61)$ & $17(13.71)$ & $124(100.0)$ & 94 (83.93) & $2(1.78)$ & $16(14.28)$ & $112(100.0)$ \\
\hline & \multicolumn{4}{|c|}{$\chi^{2}=4.71(\mathrm{df}=2, p=.095)$} & \multicolumn{4}{|c|}{$\chi^{2}=4.10(\mathrm{df}=2, p=.129)$} \\
\hline
\end{tabular}

Values are presented as number (\%).

$\mathrm{H1}$ =1st grade in high school; $\mathrm{M} 2=2$ nd grade in middle school.

\section{(25.00\%)이었다.}

다문화청소년은 출생배경국과는 상관없이 대부분 한국어만을 사용하고 있었으며(105명, 84.68\%), 한국어와 부모나라말 모두를 사용하거나(17명, 13.71\%), 부모나라말만 사용하는(2명, 1.61\%) 다 문화청소년은 다문화청소년 전체 124 명 중 19 명(15.32\%)으로 소수 였다(Table 10). 즉, 다문화청소년의 출생배경(한국 출생, 외국 출 생)은 대부분 한국이었으며 $\left[\chi^{2}(1, \mathrm{~N}=126)=70.13, p<.001\right]$, 사용 하는 언어는 대부분 한국어로 출생배경에 따라 사용하는 언어(한 국어, 외국어, 한국어와 외국어 모두 사용)는 차이를 보이지 않았 다 $\left[\chi^{2}=4.71(\mathrm{df}=2, p=.095)\right]$. 그리고 이러한 차이는 학급변화(중 학교 2학년, 고등학교 1학년)와도 관련이 없었다 $\left[\chi^{2}=4.71(\mathrm{df}=2\right.$, $\left.p=.095) ; \chi^{2}=4.10(\mathrm{df}=2, p=.129)\right]($ Table 10$)$.

다문화청소년의 출생배경에 따른 SCC 분석 결과 .05 이하 수준 으로 유의미한 차이를 보인 SCC는 없었다. 하지만 다문화청소년이 고등학교 1학년이었을 때 $\mathrm{E} 1$ (친구의 기분을 이해하려고 노력한다; $F_{(1,112)}=2.76^{\dagger}, p=.099$ )과 E2 (친구의 생각과 감정을 잘 알 수 있다; $\left.F_{(1,112)}=3.02^{\dagger}, p=.085\right)$ 문항은 유의미한 경향성을 보였다. 즉, E1-2 와 같이 '친구의 기분과 생각과 감정에 대한 공감' 문항에 대해서는 한국에서 출생한 다문화청소년의 평가 평균이 더 높은 경향성이 나타났다(Table 11). 그리고 다문화청소년이 사용하는 언어에 따른 SCC 분석 결과에서는 유의미한차이를 보이지 않았다.

\section{논의 및 결론}

본 연구는 문화집단별(다문화청소년, 단일문화청소년) 학급변 화, 거주지역규모, 그리고 다문화청소년의 문화 - 언어배경(출생국 가, 사용언어)에 따른 사회적 의사소통 능력(SCC)을 살펴보기 위 하여, 국내 청소년 패널연구인 '2013 KELS (KEDI, 2020)' 데이터를 이용하여 분석하였다. 특히, 다문화청소년과 관련된 환경 변수인 학교급(2: 중학교 2학년, 고등학교 1학년), 지역규모(4: 서울특별시, 광역대도시, 중· 소도시, 읍 - 면지역), 문화배경(2: 한국출생, 국외출
생), 사용언어(3: 한국어, 부모나라 말, 한국어와 부모나라말 모두 사용)에 따라 SCC의 차이 및 변화를 세 가지 연구문제로 나누어 분석하였다. 연구결과에서 나타난 집단별 유의미한 차이를 보였던 측정변수들은 Table 12 에 제시하였다. 주요 결과들을 중심으로 논 의하면 다음과 같다.

첫째, 중학교 2학년 다문화청소년은 단일문화청소년보다는 ‘친구 의 기분을 이해하려고 하거나 고민을 들어주는 부분과 '대화를 할 때 어떻게 말할지를 미리 생각해보고, 청자를 고려하여 쉽고 정확 한 말을 골라 이야기하면서 말이나 몸짓으로 적극적인 반응을 보이 는 부분과같은 항목에 대해 유의미하게 낮게 평가하였다 $\left(F_{(1,5,443)}=\right.$ $5.94^{\star}, p<.05 ; F_{(1,5,443)}=9.47^{* *}, p<.005 ; F_{(1,5,443)}=4.75^{*}, p<.05 ; F_{(1,5,411)}=$ $\left.10.25^{* * *}, p<.001 ; F_{(1,5,443)}=4.69^{*}, p<.05\right)$. 중학교 2 학년 다문화청 소년은 단일문화청소년에 비하여 '친구에게 공감하는 능력'과 '청 자를 고려한 소통능력'에 대한 평가가 낮은 것을 알 수 있다. 이러한 결과는 중학교 2학년 다문화청소년이 또래에 대한 공감 및 소통에 대해 스스로 원활하지 않다고 평가하고 있음을 의미한다.

둘째, 고등학교 1학년 다문화청소년은 단일문화청소년에 비하여 '청자를 고려하여 쉽고 정확하게 말하거나 예를 들어주는 부분' 평 가에 있어 유의하게 낮았다 $\left(\mathrm{F}_{(1,5,103)}=5.23^{*}, p<.05 ; F_{(1,5,102)}=7.78^{* *}\right.$, $p<.005)$. 그리고 '친구가 칭찬을 받았을 때 공감하거나, 상대의 표 정과 몸짓으로 속마을을 이해하기, 대화시에 말이나 몸짓으로 상 대에게 적극적으로 반응해주기'와 같은 부분은 다문화청소년보다 단일문화청소년이 높게 평가하기는 했지만 유의미한 정도는 아닌 경향성만을 보였다 $\left(F_{(1,5,103)}=3.39^{\dagger}, p=.065 ; F_{(1,5,103)}=3.48^{\dagger}, p=\right.$ $\left..062 ; F_{(1,5,103)}=3.16^{\dagger}, p=.076\right)$. 고등학교 1학년 다문화청소년의 경우 는 중학교 2학년때보다는 또래에게 공감하는 능력을 높게 평가하 기는 하였지만, 청자를 고려하여 예를 들어주거나 쉽게 표현하는 의사소통 기술에 대해서는 스스로에 대해 낮은 평가를 하고 있었 다. 이러한 결과는 아마도 다문화청소년이 단일문화청소년보다 주 도적인 대화를 이끌어가는 경험이 적었기 때문에 나타난 현상일수 도 있고, 다문화청소년이 의사소통 기술에 대한 자기평가에 있어 


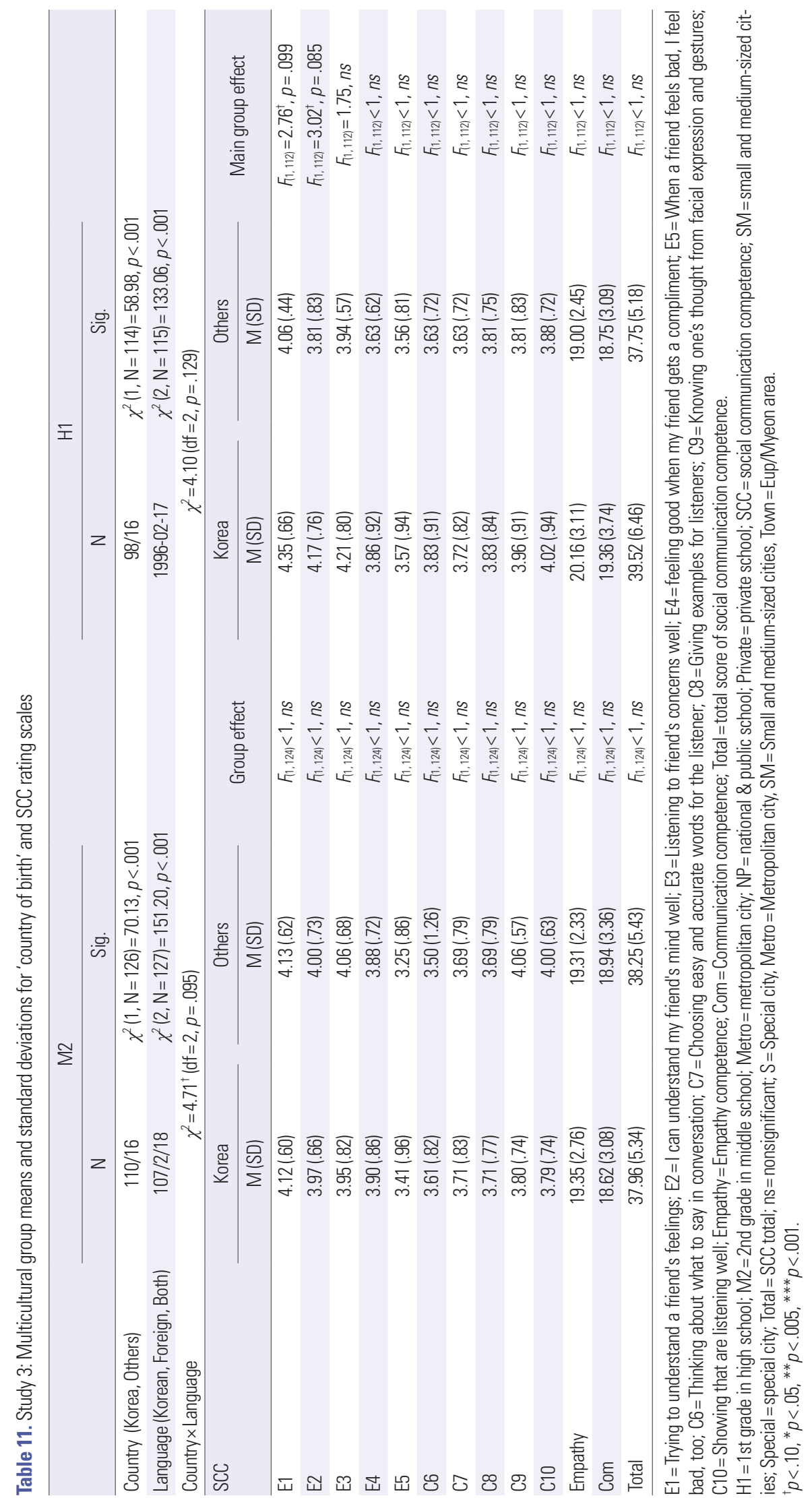




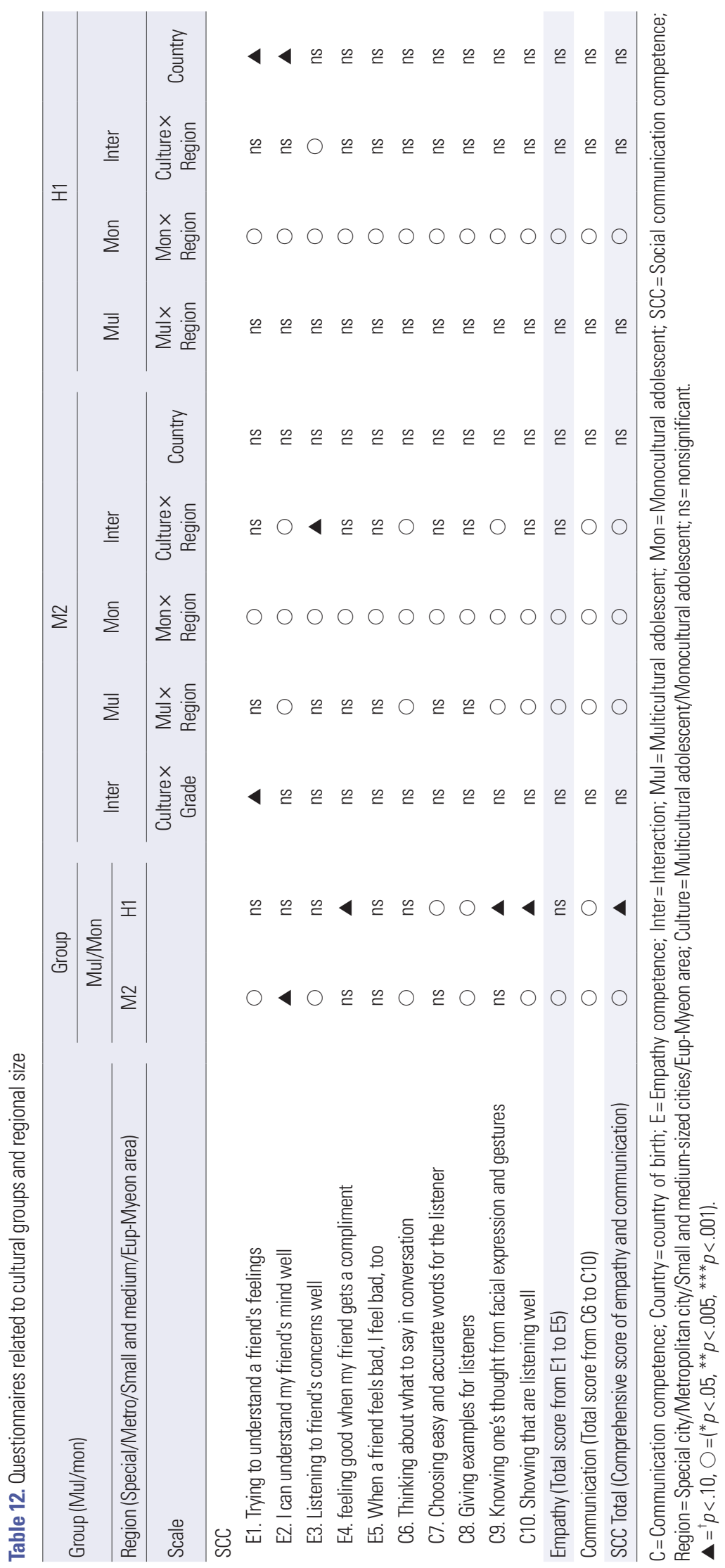


낮게 평가하는 경향이 있었기 때문일 수도 있다.

셋째, 문화집단별(다문화, 단일문화) 학급변화(중학교 2학년, 고 등학교 1학년)에 따라 SCC 개별 문항의 변화 이외에 공감능력과 소통능력, 그리고 SCC 종합점수의 변화를 비교하여 보았을 때, 중 학교 2학년때는 공감, 소통, SCC 종합점수 모두에 대해 단일문화청 소년이 유의미하게 더 높은 평가를 하는 것으로 나타났다. 하지만 고등학교 1학년 때는 소통능력에 대해서만 단일문화청소년이 유의 미하게 더 높은 평가를 하였고 나머지 공감능력과 SCC 종합점수 에서는 집단간 유의미한 평가 차이가 나타나지 않았다. 즉, 다문화 청소년은 중학교 2학년에서 고등학교 1학년으로 학급이 변화하면 서 공감에 대한 평가가 크게 상승한 것을 알 수 있었다. 공감 평가에 대한 문화집단별 차이에 대한 결과가 다문화청소년의 환경적인 영 향에 의해서인지 또는 문화적 요서에 의해서인지는 이번 연구를 통 해서는 잘 드러나지 않았다. 다만 또래 공감에 대해 다문화청소년 이 중학교 2학년때는 낮은 평가를 하다 고등학교 1학년 시기에 이 르러서는 단일문화집단과 차이를 보이지 않았다는 것은 주관적인 자기평가가 상승한 것으로 해석할 수 있다.

넷째, 문화집단(다문화청소년, 단일문화청소년) 학급별(중학교 2 학년, 고등학교 1학년) SCC 차이 분석 결과, 다문화청소년의 경우 중학교 2학년에서 고등학교 1학년으로 학급이 변화하면서 '친구의 기분을 이해하려고 노력하는 부분'의 평가가 단일문화청소년에 비 하여 상승하는 경향이 있었다 $\left(F_{(1,10,548)}=2.76^{\dagger}, p=.096\right)$. 즉 다문화 청소년은 단일문화청소년에 비하여 중학교 2 학년때는 '친구의 기 분을 이해하려고 하거나 고민을 들어주는 부분'과 '대화내용을 생 각해서 청자를 고려하여 이야기하면서, 적극적인 반응을 보이는 부분'에 대한 평가가 낮았지만, 고등학교 1학년이 되었을 때는 친구 를 이해하려고 노력하는 부분에 대한 평가가 상승하고 단지 '청자 를 고려하여 정확한 말을 골라 예를 들어 설명하는 부분'에서만 단 일문화청소년보다 평가 평균이 낮았다. 이와 같은 결과를 통해 '정 확한 말을 골라 예를 들어 설명하는 것'에 대해 문화적 배경이 다른 소수 집단 다문화청소년은 스스로에 대해 낮은 평가를 하고 있음 을 알수 있었다.

다섯째, 중학교 2학년 다문화청소년은 거주지역별 평균 점수를 통해 살펴보았을 대 서울특별시에 거주하는 다문화청소년이 SCC 점수와 개별 문항 평가가 가장 높았으며, 다음으로는 읍. 면지역, 중 · 소도시, 광역대도시 순이었다. 그리고 다문화청소년 지역규모 집 단에 따른 유의미한 차이가 나타난 SCC 문항은 '친구의 생각과 감 정을 이해하는 공감능력, '대화를 할 때 미리 생각하면서, 상대방 의 표정과 몸짓으로 속마음을 이해하면서, 상대방에게 듣고 있음 을 말이나 몸직으로 잘 반응해주는 소통 부분'에 대한 것들이었다.
하지만 다문화청소년과는 달리, 중학교 2학년 단일문화청소년은 SCC 점수와 모든 10 개 개별 SCC 문항이 거주지역규모에 따라 유의 미한 차이를 보이고 있었다. 단일문화청소년은 서울특별시와 광역 대도시 집단의 SCC 평가가 유사한 수준으로 높았으며 다음으로 지 역규모가작은 중·소도시와읍.면지역 집단의 평가가 유사한 수준 으로 낮게 평가되었다(Table 8). 즉 문화집단별로 거주지역규모에 따른 SCC 점수와 개별 평가 문항은 차이가 있었다. 특히 SCC 개별 문항 평가에 있어 다문화청소년의 경우는 '친구와의 감정공감, 대 화 기술적인 문항이 서울특별시와 읍.면지역 집단에서 광역대도시 와 중·소도시 집단보다 높게 나타나는 현상이 나타났다. 하지만, 단 일문화청소년의 경우는 SCC 개별 문항 전체에서 지역규모 크기에 따라서 서울특별시와광역대도시 집단의 평가가중·소도시와읍·면 지역 집단보다 높게 나타났다. 이처럼 문화집단별 지역규모에 따른 $\mathrm{SCC}$ 가 다르게 나타난 것은 국내 다문화청소년과 단일문화청소년 의 거주지역이 차이가 있었기 때문일 수 있다. 2020년 교육부 자료 에 의하면 국내 다문화학생의 거주 지역 비율을 구분하여 보았을 때 경기, 서울에 가장 많이 재학하고 있으며, 전체 학생 대비 다문화 학생 비율은 전남, 충남이 가장 높은 것으로 나타났다. 그리고 다문 화학생 중 중도입국 · 외국인학생 비중은 서울(39\%), 경기(32\%)가 높 으며, 국내 출생 다문화학생 비중은 전남전북(95\%)이 높은 것으로 나타났다(Ministry of Education, 2020b). 즉, 다문화학생이 가장 많이 거주하는 서울특별시나 국내 출생 다문화학생의 비율이 높 은 전남·전북 읍.면지역에서의 SCC가 높게 평가된 것으로 볼 수 있 다. 이러한 결과를 통해 다문화청소년은 다문화청소년의 수가 많거 나 다문화청소년의 비율이 높은 지역에 거주하는 다문화청소년이 $\mathrm{SCC}$ 를 높게 평가한 것으로 해석할 수 있다. 그러므로 국내 다문화 사회의 특성을 잘 알고 있는 것이 다문화청소년의 SCC 결과를 해 석하는데 있어 선행조건이 되어야 할 것으로 보인다.

여섯째, 문화집단과 지역규모의 SCC 평가 상호작용 분석 결과, 서울특별시에 거주하는 다문화청소년은 단일문화청소년보다 SCC 점수와 개별 문항 평가가 높았지만, 광역대도시에 거주하는 다문화청소년은 단일문화청소년보다 SCC 점수가 아주 많이 낮았 다. 즉, 거주규모 집단별로만 구분하였을 때는 가장 낮은 SCC점수 를 보인 것은 광역대도시에 거주하는 다문화청소년 집단이었으며, 다음으로는 중-소도시에 거주하는 다문화청소년이었다. 그리고 읍. 면 지역에 거주하는 청소년은 다문화청소년과 단일문화청소년 간 에 SCC 점수는 유사하였다(Figure 1). 이러한 결과에서 특징적인 것은 광역대도시에 거주하는 다문화청소년의 SCC가 단일문화청 소년보다도 낮고, 문화집단과 거주지역규모 집단 중에서도 가장 낮 은 평가를 보였다는 점이다. 이러한 현상에 대한 이해를 위해서는 
E2

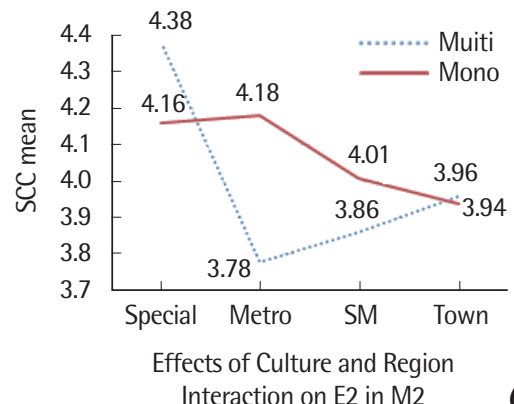

C9

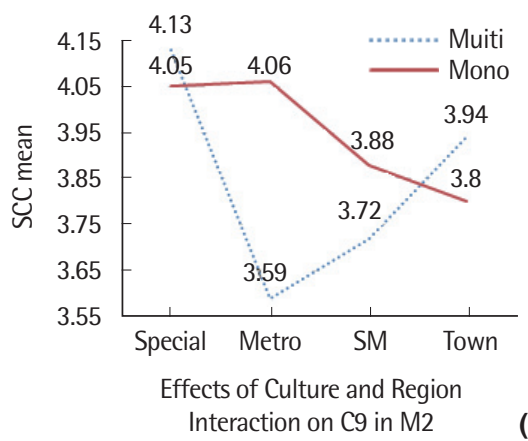

E3

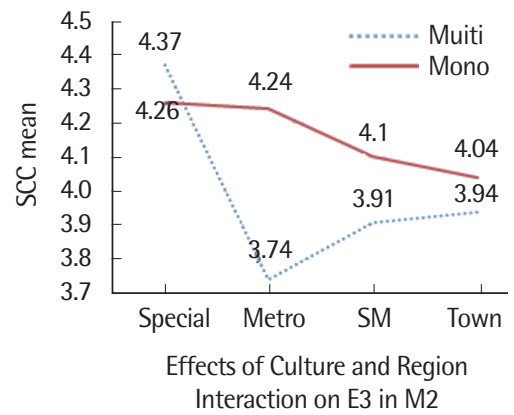

Com

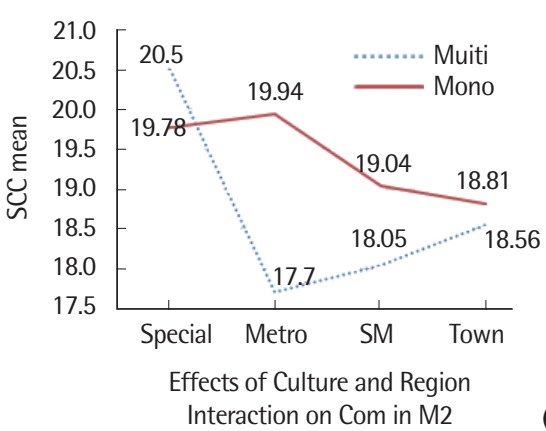

C6

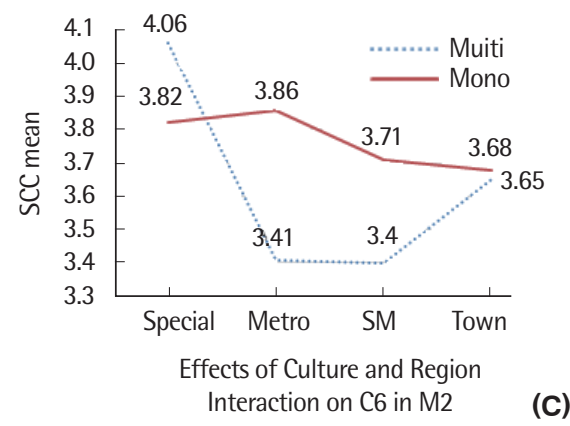

Total

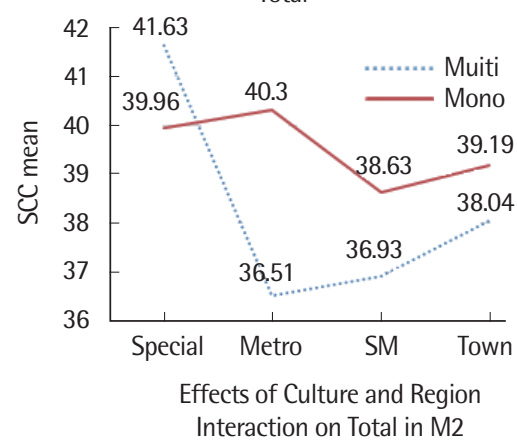

(C)

Figure 1. Effects of Culture and Region Interaction in M2. E2 = I can understand my friend's mind well; E3=Listening to friend's concerns well; C6= Thinking about what to say in conversation; $\mathrm{C} 9=$ Knowing one's thought from facial expression and gestures; $\mathrm{Com}=\mathrm{Communication}$ competence; Total=total score of social communication competence; M2 =2nd grade in middle school; SCC=Social Communication Competence; Special=Special city; Metro= Metropolitan city; SM=Small and medium-sized cities; Town=Eup/Myeon area; Mono=Monocultural adolescent; Multi= Multicultural adolescent.

지역규모에 따른 환경특성을 살펴볼 수 있어야 해석이 가능할 것으 로 보인다. 하지만 제한된 자료내에서 예측해보면 다문화청소년의 경우 광역대도시에 거주하는 집단의 사회적 의사소통 환경이 지역 규모 집단 중 가장 열악할 가능성이 있다. 또한 광역대도시에 거주 하는 다문화청소년은 자신의 사회적 의사소통 능력에 대한 평가를 매우 낮게 평가하는 성향이 있었을 가능성도 있다.

일곱째, 중학교 2학년에서 고등학교 1학년이 되었을 때 다문화청 소년은 지역규모에 따라 SCC 점수와 개별 문항에 대한 평가에 있 어 유의미한 차이를 보이지 않았다. 하지만 단일문화청소년은 고등 학교 1학년이 되었을 때도 중학교 2학년때처럼 지역규모에 따라 $\mathrm{SCC}$ 점수와 개별 문항 평가의 모든 측정변수에 유의미한 차이를 보이고 있다(Table 9). 특징적인 것은 다문화청소년의 경우는 서울 특별시 거주지역 집단의 SCC 점수와 개별 문항에 대한 평가가 중 학교 2학년 때보다 평균 점수가 낮아졌다. 그리고 이외 광역대도시, 중 - 소도시, 읍 · 면지역의 SCC는 상승하였다. 그러므로 지역규모 집단의 차이가 중학교 2학년때와는 달리 고등학교 1학년때는 유의 미하지 않게 나타났다. 단일집단의 경우는 읍 - 면지역의 SCC 상승 정도가 가장 높기는 하였지만 지역규모 집단의 SCC가 모두 상승하
였다. 그러므로 단일문화청소년의 지역규모에 따른 SCC는 중학교 2학년때와 유사하게 차이를 보이는 것으로 나타났다(Table 9). 서 울특별시에 거주하는 다문화청소년의 SCC 평가가 중학교 2학년에 서 고등학교 1학년으로 학급이 상승하면서 낮아진 것은 이례적인 결과였다. 다른 지역규모 집단들은 학급상승에 따라 SCC 평가가 높아졌는데, 왜 서울특별시에 거주하는 다문화청소년의 경우는 낮 아졌을까? 이에 대한 결과 해석을 위해서는 좀 더 다문화청소년의 환경적인 조사가 이루어져야 정확하겠지만, 일단 예상을 해본다면 문화집단과 거주지역규모 집단 중에서 가장 높은 SCC 평가를 보인 서울특별시 다문화청소년은 학급이 상승하면서 공감과 소통보다 는 학습적인 측면에 매진하면서 친구와 주변사람에 대한 공감과 소통에 대해 현재의 상황에서는 낮게 평가한 것일 수도 있다. 단일 문화청소년보다는 사회적 경쟁에 있어 좀 더 민감할 수 있는 소수 집단이라는 특성이 이러한 결과에 영향을 미쳤을 수 있다. 그리고 서울특별시에 거주하는 다문화청소년의 SCC가 단일문화청소년 집단보다 중학교 2 학년때는 더 높았지만 고등학교 1 학년때는 두 집 단 간의 SCC 평가는 유의미한 차이를 보이지 않았다. 이러한 결과 에 대해 서울특별시 거주 다문화청소년의 SCC가 연령 증가에 따 
라 낮아졌다고 평가하기보다는, 두 집단은 연령이 증가하면서 스스 로의 SCC를 유사한 수준으로 평가하게 된 것으로 해석할 수 있다. 즉, 다문화 환경적인 여건에서는 자신의 SCC를 좀 더 높게 평가하 고 있다가 이후 연령이 증가하면서 좀 더 많은 사회적 소통 기회를 가지면서 자신에 대한 평가를 더욱 엄격하게 했을 가능성도 있다.

여덟째, 문화집단별 지역규모에 대한 SCC 평가 상호작용결과 유 의미한 차이가 나타난 것은 유일하게 $\mathrm{E} 3$ (친구들의 고민을 잘 들어 준다; $\left.F_{(3,5,075)}=2.96^{*}, p<.05\right) 1$ 개 문항이었다(Table 9, Figure 2). 다 문화청소년 읍. 면지역 집단이 '친구들의 고민을 잘 들어준다'고 평 가한 것이 타 문화 · 지역규모 집단보다 월등히 높게 나타나면서 유 의미한 상호작용 효과가 나타났다. 이러한 결과는 제한적인 정보내 에서 다음의 두가지 측면으로 해석할 수 있다. 우선, '친구의 고민을 잘 들어주는 것'은 의사소통 기술적 측면에서는 기본 요건으로 의 사소통 상대자에 대한 배려와 여유가 있어야 가능하다. 그러므로 이러한 의사소통 기술에 대해 스스로를 높게 평가하고 있는 것에 대해 읍 - 면지역에 거주하는 다문화청소년이 타 문화 - 지역규모 집 단보다 또래관계에 대한 배려와 여유가 있는 것으로 해석할 수 있 다. 그리고 이러한 결과를 또 다른 측면에서 해석해보면, 친구의 고 민을 들러 준 적이 있었을 때 자신에 대해 높은 평가가 가능했을 것 으로 보이므로, 다문화청소년 읍 - 면지역 집단이 친구에게 고민을 이야기하고 들어주는 관계가 다른 문화집단별 지역규모 집단보다 더 잘 형성되어 있었을 가능성도 있다.

아홉째, 다문화청소년의 출생배경에 따른 SCC 분석 결과 .05 이 하 수준으로 유의미한 차이를 보인 SCC는 없었다. 하지만 다문화 청소년이 고등학교 1학년이었을 때 $\mathrm{E} 1$ (친구의 기분을 이해하려고 노력한다; $F_{(1,112)}=2.76^{\dagger}, p=.099$ )과 $\mathrm{E} 2$ (친구의 생각과 감정을 잘 알

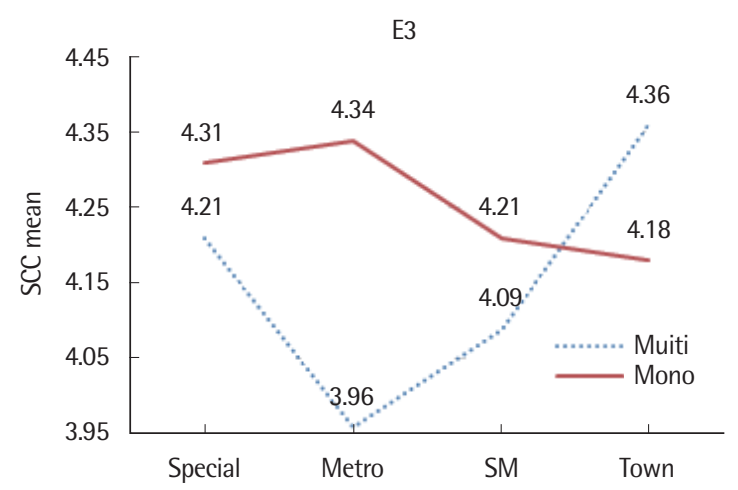

Figure 2. Effects of Culture and Region Interaction on E3 in H1. E3= Listening to friend's concerns well; $\mathrm{H1}=1$ st grade in high school; Special = Special city; Metro= Metropolitan city; SM=Small and medium-sized cities; SCC = Social Communication Competence; Town=Eup/Myeon area; Mono=Monocultural adolescent; Multi=Multicultural adolescent.
수 있다; $\left.F_{(1,112)}=3.02^{\dagger}, p=.085\right)$ 문항은 유의미한 경향성을 보였다. 즉, $\mathrm{E} 1$ 과 2 와같이 '친구의 기분과 생각과 감정에 대한 공감' 문항에 대해서는 한국에서 출생한 다문화청소년의 평가가 더 높은 경향성 이 나타났다(Table 11). 그리고 다문화청소년이 사용하는 언어에 따른 SCC 분석 결과에서는 유의미한 차이를 보이지 않았다. 즉 다 문화청소년은 거주지역규모와 학급변화에 따라서는 SCC가 차이 를 보였지만 문화 - 언어 배경은 SCC에 거의 영향을 미치지는 않았 다. 단지 한국에서 출생한 다문화청소년이 외국에서 출생한 대상 자들보다 더 ‘또래 친구의 기분을 이해하려고 노력하며, 친구의 생 각과 감정을 잘 이해하는 경향’이 나타났다. 이러한 현상은 문화배 경이 SCC에 유의미한 영향을 미치지는 않지만 경향성은 있음을 나타내는 것으로 해석할 수 있다. 하지만 출생배경, 언어사용 등에 따른 분석에 있어 다문화청소년의 집단 수가 매우 적었다는 한계가 있어 연구결과에 대한 일반화와 해석에 있어 제한적이었다.

이상의 연구결과를 통해, 본 연구에서 시사하는 바는 SCC 문항 평가와 점수는 문화집단과 거주지역, 문화배경 요인에 의해 영향을 받을 수 있다는 것이다. 그러므로 임상가는 다문화청소년에 대한 SCC 평가와 평가결과에 대한 해석, 그리고 중재 있어 거주 및 문화 배경 요인을 고려해야한다. 그리고 연구자는 SCC 문항 개발에 있 어 위의 요인들을 통제하거나 평가결과에 적용할 수 있는 안을 마 련하는 것이 바람직할 것이다.

위와 같은 주요연구 결과 및 시사점을 종합하여 임상적용 방안 에 대해는 네가지 관점에서 논의할 수 있다. 첫째, 문화집단에 따라 SCC 평가는 차이를 보였는데, 중학교 2학년때는 문화집단에 따라 차이를 보이는 SCC 측정변수들의 수가 더 많았지만, 고등학교 1학 년으로 학급이 상승하면서 차이 변수의 수는 줄었다. 그러나 여전 이 문화집단별로 차이를 보이는 SCC는 '청자를 고려하여 쉽고 정 확한 말을 선택하여, 예를 들어 설명하는 부분과 같은 의사소통 기 술 측면이었다. 다문화사회이건 단일문화사회이건 모든 문화에서 는 사회적 의사소통체계 내에 주류 문화의 우세언어가 존재하며 이 러한 우세언어는 문화자본(cultural capital)의 역할을 한다. 특히 의사소통 기술이 요구되는 복잡한 사회적 상황에서는 더욱 그러하 다(Mey, 2016). 그러므로 소수의 다문화청소년들은 의사소통 상황 에서 대화 상대방 또는 또래친구를 고려한 언어선택과 예를 들어 설명해야 하는 상위의 의사소통 기술이 요구되는 조건에 대해 자 신의 SCC를 낮게 평가할 가능성이 있다. 그러므로 임상가는 의사 소통 환경에 있어 약자에 속하는 소수 언어장애 및 다문화집단을 대상으로 SCC에 대한 평가를 할 때 대상자 스스로가 규정하는 능 력에 대한 이해와함께 좀 더 심도 있는 평가를 통해 대상자에 대한 충분한 이해를 가지고 좀 더 객관적인 평가를 할 수 있어야한다. 
둘째, 다문화청소년은 중학교 2학년때는 거주지역규모에 따라 SCC 평가에 차이를 보였지만, 고등학교 1학년으로 학급이 상승하 였을 때는 지역규모에 따라 SCC 평가가 차이를 보이지 않았다. 하 지만 단일문화청소년의 경우는 연령 및 학급상승과는 상관없이 거 주지역규모에 따라 모든 SCC 측정변수에 대한 평가가 유의미한차 이를 보였다. 이러한 결과만으로 생각해볼 때는 다문화청소년보다 단일문화청소년 집단에서 지역규모에 따른 SCC 발달 차이가 더 크 게 작용하는 것으로 볼 수 있다. 그러므로 단일문화청소년을 대상 으로 SCC 평가와 중재가 적용될 때는 거주지역에 대한 배경정보를 이해하고 있는 것이 평가결과 해석 및 중재적용에 있어 도움이 될 것으로 보인다.

셋째, 문화집단과 지역규모집단 변수간의 상호작용을 분석한 결 과에서 다문화청소년의 경우는 서울특별시와 읍 - 면지역에 거주하 는 대상자들의 SCC가 높았으며 상대적으로 광역대도시에 거주하 는 대상자들의 SCC는 아주 낮게, 다음으로는 중·소도시에서 낮게 평가되었다. 하지만 단일문화집단의 경우는 지역규모 크기에 따라 서울특별시와 광역대도시의 SCC는 높았으며 다음으로는 중·소도 시, 읍 - 면지역 순이었다. 이러한 상호작용결과에 대한 해석을 이번 데이터 자료만으로 해석하는 것은 어려운 부분이다. 하지만 예상해 보건대 단일문화가정의 경우는 지역규모가 큰 지역에 거주할수록 가정내 SES가 높을 수 있지만, 다문화가정의 경우는 서울특별시와 읍 - 면지역 거주 대상자들의 SES가 더 높고 광역대도시와 중 - 소도 시에 거주하는 대상자들의 SES가 더 낮을 수 있다. 그 중에서도 특 히 광역대도시에 거주하는 다문화청소년의 SES가 가장 낮을 가능 성이 있다. 정확한 해석을 위해서는 추가 조사와 분석이 이루어져 야 하겠지만 임상가들이 현장에서 다문화아동 및 청소년의 언어 변인에 대한 깊이 있는 이해를 위해서는 거주지역이 영향을 미칠 수 있다는 것을 주지해야 할 것으로 보인다. 넷째, 다문화청소년의 문화 - 언어배경에 따른 SCC는 연령증가에 따라 유의미한 차이가 없었다. 다문화청소년의 SCC 발달에 있어 문화 - 언어배경 변수보 다는, 화용 및 SCC 발달의 기본 요인으로 알려져 있는 사회 - 경제 적 변수들(가정내 수입정도, 보모의 교육수준 등)이 좀 더 작용하 는 것으로 보인다. 그러므로 다문화청소년의 SCC 평가와 중재시에 는 대상자의 $\mathrm{SES}$ 를 이해하는 것이 좀 더 중요할 것으로 보인다.

이번 연구는 KEDI의 ‘KELS' 데이터를 이용하여 전국적인 규모 의 다문화 및 단일문화청소년 데이터를 분석하였다는 장점이 있다. 하지만 측정변수인 SCC 문항이 좀 더 다양했으면 그리고 청소년 스스로 평가하는 방식 이외에 언어추론 및 화용언어 능력에 대한 직접평가, 지역규모에 대한 문화적 특성 등이 함께 평가되었다면 좀 더 다양한 결과해석이 가능하지 않았을까 하는 아쉬움이 남는다.
또한 연구문제 3 에서 126 명 다문화청소년의 출생배경과 사용언어 에 따른 SCC 프로파일 분석에 있어 외국에서 태어났거나, 외국어 또는 두가지 언어를 모두 사용하는 다문화청소년의 비율이 적었다 는 점은 집단 대표성 문제를 지닌다. 그리고 연구결과에서 광역대 도시에 거주하는 다문화청소년의 SCC 평가가 문화 - 지역규모 집 단 중 가장 낮았던 측면과 읍 - 면지역에 거주하는 다문화청소년의 SCC 평가 상승률이 유난히 높았다는 점에 대한 부분은 국내 다문 화의 지역특정적 환경 영향일 수 있다. 이후 연구에서는, 종단연구 에서 부모와 학생설문지 내용을 함께 분석하여 위와 같은 문화집 단별 지역규모의 SCC 평가 차이 문제에 대한 다양한 결과 해석을 해보면 좋을 것이다.

\section{REFERENCES}

Capone, A., \& Mey, J. L. (2015). Interdisciplinary studies in pragmatics, culture, and society (Vol. 4). New York: Springer.

Cha, S. E., \& Ryu, J. (2019). Asian migration background and psychosocial adaptation of adolescents in multicultural families: migration background, barriers, or resources? Korea Journal of Population Studies, 42(3), 2019.9, 55-81.

Claudia, B. (2017). Is there really a need for assessing intercultural competence?: some ethical issues. Journal of Intercultural Communication, 44(1), $1-18$.

Clouet, R. (2013). Understanding and assessing intercultural competence in an online environment: a case study of transnational education programme delivery between college students in Ulpgc, Spain, and Ices, France. Resla. Revista Espanola de Linguistica Aplicada, 26, 139-157.

Crago, M. B., \& Cole, E. (1991). Using ethnography to bring children's communicative and cultural worlds into focus. In T. Gallagher (Ed.), Pragmatics of language: Clinical practice issues (pp. 99-131). San Diego, CA: Singular.

Crago, M. B., \& Ericks-Brophy, A. (1994). Culture, conversation, and interaction. In. J. F. Duchan, L. Hewitt, \& R. M. Sonnenmeier (Eds.), Pragmatics from theory to practice (pp. 43-58). Englewoods Cliff, NJ: Prentice Hall.

Cummings, L. (2009). Clinical pragmatics. Cambridge: Cambridge University Press.

Cummings, L. (2014). Pragmatic disorders. Cham: Springer.

Cummings, L. (2015). Pragmatic and discourse disorders: a workbook. Cambridge, England: Cambridge University Press.

Delpit, L. (1995). Other people's children. New York, NY: The New Press.

Dolgin, K. G. (2018). The adolescent: development, relationships, and culture 
(14th ed.). New York, NY: Pearson.

Dollaghan, C. A., Cambell, T. E., Paradise, J. L., Feldman, H. M., Janosky, J. E., Pitcairin, D., \& Kurs-Lasky, M. N. (1999). Maternal education and measures of early speech and language. Journal of Speech, Language, and Hearing Research, 42(6), 1432-1443.

Dennis, M., Simic, N., Bigler, E. D., Abildskov, T., Agostino, A., Taylor, H. G., Rubin, K., Vannatta, K., Gerhardt, C. A., Stancin, T., \& Yeates, K. O. (2013). Cognitive, affective, and conative theory of mind (ToM) in children with traumatic brain injury. Developmental Cognitive Neuroscience, 5, 25-39.

Greenfield, P. M., \& Cocking, R. R. (1994). Cross-cultural roots of minority child development. Hillsdale, NJ: Erlbaum.

Goldstein, H., Kaczmarek, L. A., \& English, K. M. (2002). Promoting social communication: children with developmental disabilities from birth to adolescence. Baltimore: Paul H. Brookes Pub. Co.

Harry, B. (1992). Cultural diversity and the special education system: communication and empowerment. New York, NY: Teachers College Press.

Hart, B., \& Risley, T. R. (1995). Meaningful differences in the everyday experience of young American children. Baltimore, MD: Paul H Brookes Publishing.

Hoff, E. (2003). The specificity of environmental influence: socioeconomic status affects early vocabulary development via maternal speech. Child Development, 74(5), 1368-1378.

Hofstede, G. (2001) Culture's Consequences: comparing values, behaviors, institutions, and organizations Across nations (2nd ed.). Thousand Oaks, CA: Sage Publications.

Hofstede, G., Pederson, P. B., \& Hofstede, G. (2002). Exploring culture: exercises, stories, and synthetic cultures. ME: Intercultural Press.

Huttenlocher, J., Vasilyeva, M., Cymerman, E., \& Levine, S. (2002). Language input and child syntax. Cognitive Psychology, 45(3), 337-374.

Hwa-Froelich, D. A. (2015). Social communication development and disorders. NY: Psychology Press.

Kalyanpur, M., \& Harry, B. (1999). Culture in special education. Baltimore, MD: Brookes.

Kang, Y., Park, S. H., Lim, H. J., Park, B. Y., Im, H. N., Jeong, D. C., \& Bae, J. H. (2013). A study on the integrated survey and management of educational statistics. Seoul: Korea Educational Development Institute.

Kim, J. Y., \& Lee, Y. S. (2020). Parental roles in school adaptations of children from multi-cultural families: focusing on school grade. Korea Journal of Population Studies, 43(3), 77-104.

Kim, S. J., \& Hong, C. H. (2017). The effect of discrimination experience and language problems on psychosocial adjustment in children with multicultural family: The moderating effect of ego-resilience and family strengths. Korean Journal of Youth Studies, 24(1), 195-211.

Kim, S. K. (2013). A study on the multicultural youth profile survey and policy measures. Research Report of National Youth Policy Institute, 1-203.

Kim, Y., Namgung, J., Park, K. H., Choi, I. H., Kang, H., Kim, M. S., \& Lee, K. (2016). The 2016 Korea Education End Research (KELS) 2013 (IV)-survey overview report. Seoul: Korea Educational Development Institute (Technical Report TR 2016-55-01).

Korea Educational Development Institute. (2020). 147th KEDI educational policy forum free semester system and student competency change: recognition of student competency in 2019 free semester system. Seoul: Korea Educational Development Institute (RRM 2020-01).

Lane, S. D. (2010). Interpersonal communication: competence and contexts (2nd ed.). Boston: Allyn \& Bacon, Pearson Education, Inc.

Larson, V. L., \& McKinley, N. L. (1998). Characteristics of adolescents' conversations: a longitudinal study. Clinical Linguistics and Phonetics, 12(3), 183-203.

Leaper, C., \& Robnett, R. (2011). Women are more likely than men to use tentative language, aren't they?: a meta-analysis testing for gender differences and moderators. Psychology of Women Quarterly, 35(1), 129-142.

Lee, E. J. (2020). Data mining decision tree models of multicultural acceptability of multicultural adolescents in Korea: focusing on language skills (listening, speaking, reading, writing) of Korean and mother's native languages. Communication Sciences \& Disorders, 25(2), 299-317.

LMTF. (2013). Toward universal learning-recommendations from the learning metrics task force. Montreal and Washington D. C.: UNESCO Institute of statistics and center for universal education at Brookings Institution.

Marotz, L. R., \& Allen, K. E. (2016). Developmental profiles: pre-birth through adolescence (8th ed.). Belmont, CA: Wadsworth/Cengage Learning.

McCormick, C. B., \& Scherer, D. G. (2018). Child and adolescent for educators (2nd ed.). New York: The Guilford Press.

Mey, J. L. (2016). Interdisciplinary studies in pragmatics, culture, and society. In A. Capone \& J. L. Mey (Eds.), Interdisciplinary studies in pragmatics, culture, and society (pp. 15-41). New York: Springer.

Ministry of Gender Equality and Family. (2019). National multicultural family survey Report (http://www.mogef.go.kr/). Seoul: MGEF.

Ministry of Education. (2020a). Education statistics. Retrieved from http:// www.moe. go.kr/web/100085/site/contents/ko/ko_0120.jsp?selectId=1085. Ministry of Education. (2020b). A plan to support multicultural education in 
2020 for starting line equality. Sejong: Education Opportunity Guarantee Department of the Ministry of Education.

Müller, N. (Ed.). (2000). Pragmatics in speech and language pathology: studies in clinical applications (Vol. 7). Philadelphia, PA: John Benjamins.

Muma, J. R. (1991). Experiential realism: clinical implication. In T. Gallagher

(Ed.), Pragmatics of language: clinical practice issues (pp. 229-247). San Diego, CA: Singular.

Namgung, J., Kim, Y., Park, K. H., Jeong, D. C., Park, H., \& Kim, Y. W. (2015). KEDI student competence survey study: development and validation of survey tools. Seoul: Korea Educational Development Institute (Study Report RR 2015-31).

Namgung, J., Kim, Y., Park, K. H., Choi, I. H., Park, H., \& Jeong, S. E. (2016). 2016 KEDI student competency study. Seoul: Korea Educational Development Institute (Study Report RR 2016-13).

Namgung, J., Kim, H., Park, K. H., Song, S. W., Kim, Y., \& Lee, K. M. (2018). 2018 Korea Education End Research (KELS) 2013 (VI)-survey overview report. Seoul: Korea Educational Development Institute (Technical Report TR 2018-137).

National Youth Policy Institute. (2020). Multicultural Youth Panel Survey: 1st to 8th year youth survey table. Seoul: Korea Youth Policy Institute.

Nippold, M. A. (2007). Later language development: school-age children, adolescents, and young adults (3rd ed.). Austin, TX: Pro-Ed.

OECD. (2002). Definition and Selection of Competencies (DeSeCo): theoretical and conceptual foundations strategy paper. Paris: OECD Publishing.

Qi, C. H., Kaiser, A. P., Milan, S., \& Hancock, T. (2006). Language performance of low-income African American and European American preschool children on the PPVT-III. Language, Speech, and Hearing Services in Schools, 37(1), 5-16.

Qi, C. H., Kaiser, A. P., Milan, S. E., Yzquierdo, Z., \& Hancock, T. B. (2003). The performance of low-income, African American children on the preschool language scale-3. Journal of Speech, Language and Hearing Re- search, 46(3), 576-590.

Raffaelli, M., \& Duckett, E. (1989). “We were just talking...”: conversations in early adolescence. Journal of Youth and Adolescence, 18(6), 567-582.

Rawlins, W. K. (1992). Friendship matters: communication, dialectics, and the life course. New York: Aldine De Gruyter.

Reed, V. A. (2012). An introduction to children with language disorders (4th edition). NJ: Pearson.

Reliable Ministry of Government Legislation. (2020). National law information center. Retrieved from http://www.law.go.kr/.

Statistics Korea (2020). Korean statistical information service (KOSIS). Sejong: Author.

Steinberg, L. D. (2020). Adolescence (12th ed.). New York, NY: McGraw-Hill Education.

Tannen, D. (1990). You just don't understand: women and men in conversation. New York: Macmillan.

Terrell, S. L., \& Terrell, F. (1996). The importance of psychological and sociocultural factors in providing clinical services to African American children. In A. G. Kamhi, K. E. Pollock, \& J. L. Harris (Eds.). Communication development and disorders in African children (pp. 55-72). Baltimore, MD: Brookes.

Triandis, H. C. (1995). Individualism and collectivism. Boulder, CO: Westview Press.

Vygotsky, L. (1986). Thought and language (A. Kozulin, Trans.). London, UK: MIT Press.

Wertsch, J. V. (1985). Vygotsky and the social formation of mind. Cambridge, MA: Harvard University Press.

Yang, G. M. (2013). A study on the multicultural youth profile survey and policy measures. Seoul: Korea Youth Policy Study.

Yang, G. M., \& Kim, J. (2018). Multicultural youth profile study 2018: New panel design report. Korea Institute for Youth Policy Studies, 1-135. 
Appendix 1. Communicative competence questionnaire

\begin{tabular}{|c|c|c|c|c|c|c|c|}
\hline \multicolumn{3}{|c|}{ 다음의 각 문장에 대해 학생이 동의하는 정도에 동그라미 $(\bigcirc)$ 하여 주십시오. } & \multirow{2}{*}{$\frac{\text { 전혀 그렇지 않다 }}{\text { (1) }}$} & \multirow{2}{*}{$\begin{array}{c}\text { 그렇지 않다 } \\
\text { (2) }\end{array}$} & \multirow{2}{*}{$\frac{\text { 보통이다 }}{\text { (3) }}$} & \multirow{2}{*}{$\begin{array}{c}\text { 그렇다 } \\
\text { (4) }\end{array}$} & \multirow{2}{*}{$\begin{array}{c}\text { 매우 그렇다 } \\
\text { (5) }\end{array}$} \\
\hline 공감 & 1 & 친구의 기분을 이해하려고 노력한다. & & & & & \\
\hline & 2 & 친구의 마음(생각과 감정)을 잘 알 수 있다. & (1) & (2) & (3) & (4) & (5) \\
\hline & 3 & 친구의 고민을 잘 들어준다. & (1) & (2) & (3) & (4) & (5) \\
\hline & 4 & 친구가 선생님께 칭찬을 받으면 나도 기분이 좋아진다. & (1) & (2) & (3) & (4) & (5) \\
\hline & 5 & 친구가 기분이 나쁘면 나도 기분이 나빠진다. & (1) & (2) & (3) & (4) & (5) \\
\hline \multirow[t]{5}{*}{ 소통 } & 6 & 대화를 할 때 어떻게 말할지 미리 생각하고 말한다. & (1) & (2) & (3) & (4) & (5) \\
\hline & 7 & 듣는 사람이 이해할 수 있도록 쉽고 정확한 말을 골라 이야기한다. & (1) & (2) & (3) & (4) & (5) \\
\hline & 8 & 듣는 사람이 잘 이해할 수 있도록 예를 들어 설명한다. & (1) & (2) & (3) & (4) & (5) \\
\hline & 9 & 상대방의 표정과 몸짓을 살피면서 속마음을 이해한다. & (1) & (2) & (3) & (4) & (5) \\
\hline & 10 & 대화할 때 이야기를 잘 듣고 있다는 것을 말이나 몸짓으로 보여준다. & (1) & (2) & (3) & (4) & (5) \\
\hline
\end{tabular}




\section{국문초록}

\section{다문화청소년의 사회적 의사소통 능력 프로파일 종단분석: 지역규모, 언어문화배경에 따른 중학교 2학년과 고등학교 1학년 비교 \\ 이은주}

이화여자대학교 특수교육연구소

배경 및 목적: 본 연구는 다문화청소년의 거주지역규모, 언어문화배경(출생국가, 사용언어)에 따른 사회적 의사소통 능력(SCC)을 살 펴보기 위하여, 국내 청소년 패널연구인 KEDI '2013 KELS' 데이터를 이용하여 분석하였다. 방법: 중학교 2학년 다문화청소년이 고등 학교 1학년이 되었을 때까지 문화집단별(다문화청소년, 단일문화청소년), 지역규모(특별시, 대도시, 중·소도시, 읍·면지역), 출생지역 (한국, 외국)과 사용언어(한국말, 어머니 또는 아버지 나라 말, 한국말과 어머니 또는 아버지 나라 모두 사용)에 따라서 SCC 개별 문항 평가와 점수 차이가 있는지를 다변량분석(MANOVAs)을 통해 살펴보았다. 결과: 1) 다문화청소년은 단일문화청소년에 비하여 “청자 를 고려하여 쉽고 정확하게 말하거나 예를 들어주는 부분' 평가에 있어 유의하게 낮았다 $\left(F=5.23^{*}, p<.05 ; F=7.78^{* *}, p<.005\right)$. 2) 문화 집단별 지역규모에 따른 SCC평가 상호작용 분석 결과, 서울특별시에 거주하는 다문화청소년은 단일문화청소년보다 SCC 점수와 개별 문항 평가가 높았지만, 광역대도시에 거주하는 다문화청소년은 단일문화청소년보다 SCC 평가가 전반적으로 아주 많이 낮았다 $\left(F=3.33^{*}, p<.05\right)$. 3) '친구들의 고민을 잘 들어준다'는 문항에 대해 다문화청소년 읍.면지역 집단은 타 문화·지역규모 집단보다 유의미 하게 높게 평가하였다 $\left.\left(F=2.96^{*}, p<.05\right) .4\right)$ '친구의 기분과 생각과 감정에 대한 공감' 문항에 대해서는 한국에서 출생한 다문화청소년 의 평가가 더 높은 경향성이 나타났다 $\left(F=2.76^{\dagger}, \mathrm{p}=.099\right)$. 논의 및 결론: SCC 문항평가와 점수는 거주지역 및 문화배경 요인에 의해 영 향을 받는 것으로 나타났다. 그러므로 임상가는 다문화청소년에 대한 SCC 평가와 평가결과에 대한 해석, 그리고 중재 있어 거주 및 문 화배경 등을 고려해야한다.

핵심어: 사회적 의사소통 능력, 다문화청소년, 2013 한국교육종단연구, 거주지역, 언어문화배경

본 논문은 2020년 대한민국 교육부와 한국연구재단의 지원을 받아 수행된 연구임(No. NRF-2020S1A5B5A16082517).

\section{참고문헌}

강영혜, 박성호, 임현정, 박병영, 임후남, 정동철, 배정현 (2013). 교육통계 통합조사 및 관리방안 연구. 서울: 한국교육개발원. 교육부 (2020a). 교육통계. 세종: 교육부.

교육부 (2020b). 출발선 평등을 위한 2020년 다문화교육 지원계획. 세종: 교육부 교육기회보장과.

김수진, 홍창희 (2017). 다문화가정 자녀의차별경험과 언어문제가 심리사회적 적응에 미치는 영향. 청소년학연구, 24(1), 195-211.

김승경 (2013). 다문화청소년 종단조사 및 정책방안 연구. 한국청소년정책연구원 연구보고서, 1-203.

김지영, 이윤석 (2020). 다문화가족 청소년의 학교적응과 부모의 역할: 학교급별차이를 중심으로. 한국인구학, 43(3), 77-104.

김양분, 남궁지영, 박경호, 최인희, 강호수, 김미숙, 이규민 (2016). 2016 한국교육종단연구(KELS) 2013(IV)-조사개요보고서. 서울: 한국교육개발원 (기술보고 TR 2016-55-01).

남궁지영, 김양분, 박경호, 정동철, 박현정, 김유원 (2015). KEDI 학생역량 조사 연구: 조사 도구 개발 및 타당화. 서울: 한국교육개발원 (연구보고 RR 2015-31).

남궁지영, 김양분, 박경호, 최인희, 박현정, 정승은 (2016). $2016 \mathrm{KEDI}$ 학생역량 조사 연구. 서울: 한국교육개발원(연구보고 RR 2016-13).

남궁지영, 김혜자, 박경호, 송승원, 김양분, 이규민 (2018). 2018 한국교육종단연구(KELS) 2013(VI)-조사개요보고서. 서울: 한국교육개발원 (기술보

고 TR 2018-137).

법제처 (2020). 국가법령정보센터(http://www.law.go.kr/). 세종: 법제처. 
양계민 (2013). 다문화 청소년 종단조사 및 정책방안 연구. 서울: 한국청소년정책연구.

양계민, 김주영 (2018). 다문화청소년 종단연구 2018: 신규패널설계보고서. 한국청소년정책연구원 연구보고서, 1-135.

여성가족부 (2019). 전국다문화가족실태조사 통계정보 보고서(http://www.mogef.go.kr/). 서울: 여성가족부.

이은주 (2020). 다문화 청소년의 다문화 수용성 예측요인에 대한 데이터 마이닝 의사결정나무모형 분석: 한국어와 어머니 모국어에 대한 4 가지 언어

사용 능력(듣기, 말하기, 읽기, 쓰기)을 중심으로. Communication Sciences \& Disorders, 25(2), 299-317.

차승은, 유정균 (2019). 다문화가정 청소년의 심리사회적 적응: 외국인 어머니를 둔 청소 년의 이주배경을 중심으로. 한국인구학, 42(3), 55-81.

통계청 (2020). 국가통계포털(http://kosis.kr/index/index.do). 대전: 통계청.

한국청소년정책연구원 (2020). 다문화청소년패널조사: 1-8차년도 청소년용 조사표. 서울: 한국청소년정책연구원.

한국교육개발원 (2020). 제147차 KEDI 교육정책포럼 자유학기제와 학생 역량 변화: 2019년도 자유학기제 학생역량 인식. 서울: 한국교육개발원(연 구자료 RRM 2020-01).

\section{ORCID}

이은주(제1저자, 교신저자, 연구교수 https://orcid.org/0000-0003-2976-3151) 